\title{
Effects of Different Sterilization Methods on the
}

\section{Physico-Chemical and Bioresponsive Properties of Plasma-Treated PCL Films}

\author{
Rouba Ghobeira ${ }^{1 *}$, Charlot Philips $^{2 \diamond}$, Heidi Declercq ${ }^{2}$, Pieter Cools ${ }^{1}$, Nathalie De Geyter ${ }^{1}$, \\ Ria Cornelissen ${ }^{2 \circ}$ and Rino Morent ${ }^{1 \circ}$ \\ ${ }^{1}$ Research Unit Plasma Technology (RUPT), Department of Applied Physics, Faculty of \\ Architecture and Engineering, Ghent University, Ghent, Belgium
}

${ }^{2}$ Histology and Tissue Engineering Group, Department of Basic Medical Sciences, Faculty of Medicine, Ghent University, Ghent, Belgium

* Rouba.Ghobeira@Ugent.be

$\diamond$ First authors $\circ$ Last authors

ABSTRACT. For most tissue engineering applications, surface modification and sterilization of polymers are critical aspects determining the implant success. A first part of this study is thus dedicated to modify polycaprolactone (PCL) surfaces via plasma treatment using a medium pressure dielectric barrier discharge (DBD), while the second part focuses on the sterilization of plasma-modified PCL. Chemical and physical surface changes are examined making use of water contact angle goniometry (WCA), X-ray photoelectron spectroscopy (XPS) and atomic force microscopy (AFM). Bioresponsive properties are evaluated by performing cell culture tests. Results show that air and argon plasmas decrease the WCA significantly due to the incorporation of oxygen-containing functionalities onto PCL surface, without modifying its morphology. Extended treatment times lead to a PCL degradation especially in case of air plasma. Besides surface modification, the plasma potential to sterilize PCL is studied in function of appropriate treatment times, but sterility is not achieved so far. Therefore, plasma-modified films are subjected to $\mathrm{UV}, \mathrm{H}_{2} \mathrm{O}_{2}$ plasma (HP) and ethylene oxide (EtO) sterilizations. UV exposure of $3 \mathrm{~h}$ does not alter PCL physico-chemical properties. A decreased wettability is observed after EtO sterilization, attributable to the modification of PCL chain ends reacting with EtO molecules. HP sterilization increases the WCA of the plasma-treated samples, presumably due to the scission of the hydrophilic bonds generated during the previous plasma treatments. 
Moreover, HP modifies PCL surface morphology. For all the sterilizations, an improved cell adhesion and proliferation is observed on plasma-treated films compared to untreated ones. EtO shows the lowest proliferation rate compared to HP and UV. Overall, of the three sterilizations, UV is the most effective, since the physical alterations provoked by HP might interfere with the structural integrity when it comes to 3D scaffolds and the chemical modifications caused by EtO, in addition to its toxicity, interfere with PCL bioactivity.

GRAPHICAL ABSTRACT.
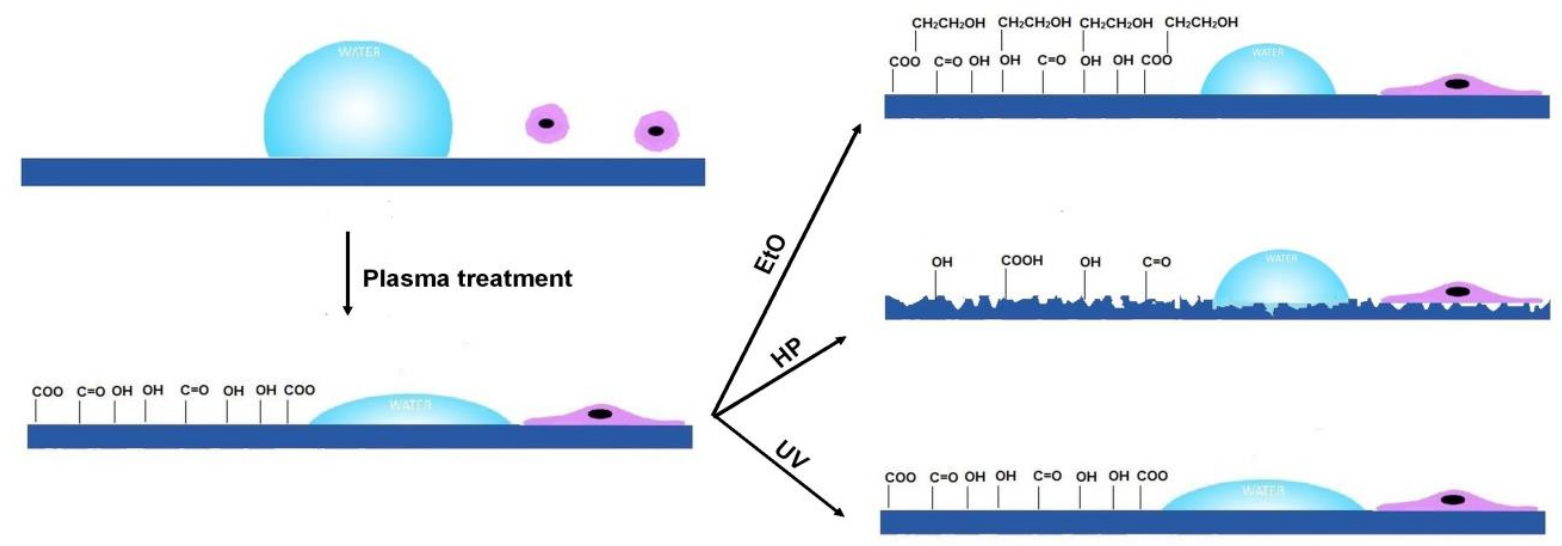

KEYWORDS. PCL, plasma treatment, sterilization methods, UV sterilization, $\mathrm{H}_{2} \mathrm{O}_{2}$ plasma sterilization, ethylene oxide sterilization, surface characterization.

\section{Introduction}

Using biodegradable polymers as biomaterials has shown significant advancements in the fields of regenerative medicine and tissue engineering ${ }^{1}$. In particular, polycaprolactone (PCL) has received considerable attention due to its excellent mechanical and structural properties and tuneable degradation kinetics. Moreover, the non-immunogenicity of PCL combined with the possibility to be used as an interporous scaffold material have resulted in a better tissue ingrowth ${ }^{2-4}$. The abovementioned benefits, in addition to the PCL inexpensive production routes, have encouraged many research groups to investigate its potential applications in numerous fields of tissue engineering ${ }^{2,5}$. However, the bioactivity of the tissue engineered constructs is threatened by the hydrophobic nature of PCL ${ }^{4,6-8}$. In general, it is known that a moderate surface hydrophilicity, allows for an increased adsorption of proteins without modifying their natural conformation. In turn, this increases the cell affinity towards the surface, leading to a stimulated cell adhesion and cell proliferation ${ }^{9-10}$. As a consequence, PCL hydrophobicity is negatively 
impacting cell-material interactions ${ }^{1}$. In order to overcome this issue, a surface modification is required. Several approaches have been previously investigated including wet-chemical treatments, ion beam, X-ray and gamma radiation. However, the wet chemical treatment route generates high amounts of hazardous chemical waste and often impacts bulk properties such as structural strength and elasticity, while most radiation methods can cause severe degradation of the polymer ${ }^{11}$. As an alternative, non-thermal plasma treatment has shown to be a promising method because it is highly versatile, only modifying the top nm layers of the polymer without altering the bulk properties $4,6,12-13$. By choosing an appropriate working gas, this treatment incorporates oxygen-containing functional groups, either directly or via post-oxidation ${ }^{14}$. These polar groups increase the surface energy and wettability and thus improve protein adsorption and cytocompatibility ${ }^{7,12}$. Many studies have shown that plasma treatment of PCL performed at low pressure enhances the adhesion and proliferation of a wide variety of cell types $4,8,12,15$ 16. As an alternative to low-pressure plasma treatments using expensive vacuum equipment, a few authors reported that atmospheric pressure plasma treatment is also effective, giving cause to a high cellular adhesion and proliferation ${ }^{7,17-18}$. Medium pressure plasma is rarely used to treat PCL, despite its potential to easily acquire a larger volume of plasma compared to atmospheric pressure plasma treatments, with relatively cost effective pumping systems ${ }^{19}$. Therefore, our research group has previously used a dielectric barrier discharge (DBD), operating in different gases at medium pressure, in order to modify PCL surface properties. Both air and argon plasmas have introduced oxygen-containing functionalities onto PCL surface and thus have increased its wettability, positively influencing the adhesion and the proliferation of human foreskin fibroblasts and mouse calvaria pre-osteoblasts ${ }^{3,20}$.

Once an efficient surface modification is accomplished, a crucial and final prerequisite for the use of PCL in vitro and in vivo is required: the material sterility ${ }^{21-22}$. Consequently, after sterilization, PCL should maintain the introduced surface properties that determine to a large extent the success of the implant. Despite the importance of the material properties, the impact of sterilization on PCL structure and surface is largely overlooked in literature, as the majority of studies solely focus on the microbial activity to check for the sterilization efficacy ${ }^{23}$.

In addition to its ability to modify surface properties, plasma treatment, especially at low pressure, has been proven as an effective process to destroy microorganisms ${ }^{24}$. Plasma sterilization at medium pressure has been rarely investigated. Etching effect, mainly induced by oxygen plasmas, is shown to be one of the sterilizing factors since it causes shrinkage and physical destruction of the microorganisms. Moreover, it has been shown that the emitted UV radiation plays a role in plasma sterilization since it can destroy the microorganism DNA. 
Particularly, UV plays a decisive role in the case of noble gas plasmas because of their limited ability to shrink the microorganisms. Therefore, oxygen-based plasmas are shown to be more effective than argon plasmas because of the synergic effect of etching and UV radiation. However, when the etch resistance of the microorganisms is higher than that of the polymer, a deterioration of the morphological and topographical organization and thus a degradation of the polymer will occur before attaining sterility. As a consequence, plasma sterilization is mostly limited to non-medical applications 25-26. Nevertheless, hydrogen peroxide gas-based sterilizations, involving plasma as part of the process, are widely used in the medical field. It is not considered a "real" plasma sterilization since the sterilizing effect is hydrogen peroxide related rather than plasma related. A detoxifying role is associated to the plasma which induces the breakdown of the remaining peroxide ${ }^{25,27}$.

A variety of non-plasma sterilization techniques can be carried out including steam autoclave, heat sterilization, gamma irradiation, ethylene oxide sterilization and UV irradiation. Because of the PCL low melting point $\left(59-64^{\circ} \mathrm{C}\right)$, autoclave involving a temperature of $121^{\circ} \mathrm{C}$ and heat sterilization involving higher temperatures soften and melt the polymer leading to a severe alteration of the morphological structure ${ }^{23,28-29}$. Gamma sterilization is one of the most popular methods for heat-sensitive materials. However, the high energy of the gamma irradiation causes ionizing reactions in polymeric chains leading to a modification of the polymer crystallinity and molecular weight widely affecting surface and bulk properties ${ }^{28,30}$. Ethylene oxide (EtO) sterilization is generally estimated to have less destructive effects on the polymer properties, but due to its high toxicity, it is progressively being banned out of EU hospitals. ${ }^{31-32}$ Peniston et al. have shown that neither EtO nor $\mathrm{H}_{2} \mathrm{O}_{2}$ plasma (HP) sterilizations affected the molecular integrity and the morphology of polylactic acid (PLA), while causing minor changes in the surface chemistry ${ }^{31}$.

UV sterilization presents a simple, effective and cheap method that was shown to preserve the biocompatibility of the sterilized material. Rainier et al. revealed that UV and HP sterilizations are effective and suitable techniques preserving the chemical and morphological features of PLA ${ }^{28}$. Extended UV irradiation for 5-24 hours, can however exert drastic changes in the topography and the chemical composition ${ }^{33}$.

Despite the sterilization drawbacks affecting the surface properties of polymers, few studies have investigated these properties when polymers are subjected to a previous surface modification. Furthermore, no study, to the best of our knowledge, has tackled the sterilization effects on plasma- activated PCL. 
The aim of this study is thus to perform a beneficial plasma surface modification of PCL films and to investigate the potential of this plasma treatment to sterilize the films. A second objective is to analyze the effects of different non-plasma sterilization methods on the physico-chemical properties and the cellular response of the plasma-treated films.

Acknowledging the above, in this study a medium pressure DBD operating in air and in argon is used to modify the surface of spin-coated PCL films. Plasma activated films are then subjected to UV, HP or EtO sterilization, after which the sterility of the films is evaluated. Three surface analysis techniques are utilized in order to assess the physico-chemical modifications occurring on the surface: static water contact angle (WCA) goniometry, X-ray photoelectron spectroscopy (XPS) and atomic force microscopy (AFM). Besides surface characterization, live/dead staining and MTT assay are also performed to evaluate the adhesion and proliferation of adipose derived stem cells (ADSCs) on PCL films.

\section{Materials and Methods}

\section{Preparation of PCL samples}

PCL films are prepared by spin coating using the SPS Polos machine (SPIN150i/200i infinite). Commercially available PCL granules (MW $=80000 \mathrm{~g} / \mathrm{mol}$ ) and tetrahydrofuran (THF) were purchased from Sigma-Aldrich (Belgium) and used to prepare a $4 \%(\mathrm{w} / \mathrm{w})$ solution. Glass cover slips having diameters of $12 \mathrm{~mm}$ (for subsequent cell culture tests) and $25 \mathrm{~mm}$ are used as substrate. A volume of $445 \mu \mathrm{l}$ is deposited on a glass cover slip and spin coated for $70 \mathrm{~s}$, at a spin speed of $3000 \mathrm{rpm}$ and a spin acceleration of $500 \mathrm{rpm} / \mathrm{s}$. Afterwards, PCL films are allowed to dry overnight to remove any residual solvent.

\section{Plasma treatment setup and plasma characterization}

The DBD reactor used to treat PCL samples, consists of two main parts, a power supply and a plasma chamber fed with controlled gas flow and connected to a pump. A schematic view of this setup is presented in Fig 1.

The plasma is generated in the plasma chamber (cylindrical enclosure) between two circular copper electrodes $($ diameter $=4 \mathrm{~cm})$, both covered with a square $\left(25.0 \mathrm{~cm}^{2}\right)$ ceramic plate $\left(\mathrm{Al}_{2} \mathrm{O}_{3}\right)($ thickness $=0.7 \mathrm{~mm})$ serving as dielectric. The superior electrode is connected to a high frequency $(50 \mathrm{kHz}) \mathrm{AC}$ power source and the inferior electrode is connected to the earth through a resistor $\mathrm{R}(50 \Omega)$ or a capacitor $\mathrm{C}(10.4 \mathrm{nF})$ used to electrically characterize the discharge. The discharge gap between the two electrodes is set to $4 \mathrm{~mm}$. As a preplasma phase, the PCL sample is fixed on the inferior ceramic plate, and the discharge chamber is pumped down by a rotary 
vane pump below a pressure of $0.6 \mathrm{kPa}$. Afterwards, the plasma reactor is filled with the discharge gas (air or argon) at a rate of 3 standard liters per minute (slm) until a sub-atmospheric pressure $(90 \mathrm{kPa})$ is reached. In order to reach a reproducible gas composition in the plasma chamber, the working gas is kept at a rate of $3 \mathrm{slm}$ for $3 \mathrm{~min}$ to flush the chamber. This purging step constitutes the end of the pretreatment phase and the plasma treatment is performed for various treatment times at a medium pressure of $5.0 \mathrm{kPa}$ and a gas flow of $1 \mathrm{slm}$.

Air and argon Alphagaz 1 are purchased from Air Liquide (Belgium).

In order to electrically characterize the DBD, the high voltage and the discharge current are measured and the current-voltage waveforms are acquired:

- The high voltage applied to the reactor is measured using a 1000:1 high voltage probe (Tektronix P6015A) connected to the superior electrode.

-The discharge current is monitored by measuring the voltage over the resistor of $50 \Omega$ connected in series to the ground.

-The current-voltage waveforms are visualized using Picoscope 6 software after being recorded with a digital oscilloscope (Picoscope 3204A).

To determine the discharge power of the $\mathrm{DBD}$, Lissajous figures are acquired. The resistor is thus replaced by a capacitor of $10.4 \mathrm{nF}$. The voltage across this capacitor is directly proportional to the charge stored on the copper electrodes. Lissajous figures are constructed by plotting the charge as a function of the applied voltage, and the discharge power is calculated by multiplying the electrical energy consumed per voltage cycle with the frequency of the feeding voltage (50 $\mathrm{kHz}$ ) knowing that the electrical energy is equal to the area enclosed by the Lissajous figure ${ }^{34}$. In this work, all plasma treatments are performed with an applied discharge power of $1.40 \mathrm{~W}$ and $1.07 \mathrm{~W}$ for air and argon respectively. 


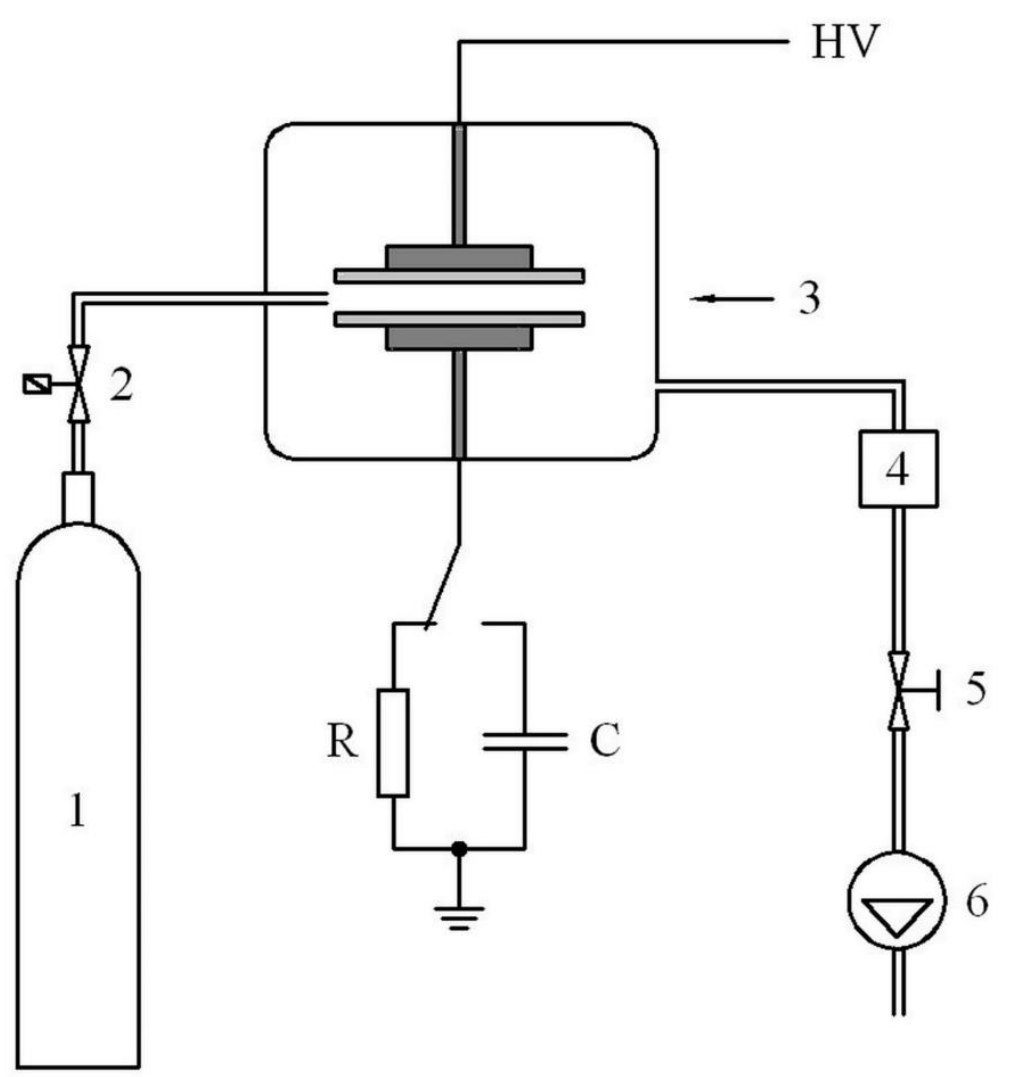

Fig 1. Schematic representation of the DBD reactor (1: gas cylinder; 2: mass flow controller; 3: plasma reactor; 4: Pressure gauge; 5: valve; 6: pump)

\section{Sterilization}

PCL films are placed in polystyrene well plates and subsequently sterilized by means of three different sterilization methods: UV irradiation, ethylene oxide (EtO) sterilization and $\mathrm{H}_{2} \mathrm{O}_{2}$ plasma (HP) sterilization.

\section{a. UV irradiation}

Samples are placed under an ultraviolet lamp of $15 \mathrm{~W}$ (Sylvania; $254 \mathrm{~nm}$ wavelength) at a distance of $45 \mathrm{~cm}$ and irradiated for $3 \mathrm{~h}$. The effective UV intensity measured at $45 \mathrm{~cm}$ from lamp surface is $300 \mu \mathrm{W} / \mathrm{cm}^{2}$.

\section{b. Ethylene oxide sterilization}

Before sterilization, samples are sealed in sterilization pouches (Steriking S6; Wipak Medical) and transferred to AZ Sint-Jan Brugge (Belgium). EtO treatment is achieved at $38^{\circ} \mathrm{C}$ and is followed by $48 \mathrm{~h}$ aeration to remove residual EtO. 


\section{c. $\underline{\mathrm{H}}_{2} \underline{\mathrm{O}}_{2}$ plasma sterilization}

Samples are sterilized with HP in the UZ hospital- Ghent (Belgium), using a STERRAD 100S (Advanced Sterilization Products; Johnson \& Johnson). A short cycle of $55 \mathrm{~min}$ is performed with temperatures not exceeding $55^{\circ} \mathrm{C}$.

\section{Sterility test}

Samples are immediately after sterilization tested for sterility. Ten samples per sterilization method are immersed in soybean casein digest broth for cultivation of fastidious microorganisms (Sigma-Aldrich; T8907) and incubated at $37^{\circ} \mathrm{C}$ for 5 days. Samples are regularly checked for clouding, which indicates contamination. Clear broth after 5 days incubation confirms efficient sterilization.

\section{Surface characterization}

\section{a. Static water contact angle (WCA)}

In order to evaluate the surface wettability of the PCL films, static contact angles are measured at room temperature, using a commercial Krüss Easy Drop optical system (Krüss Gmbh, Germany). $1 \mu$ l-drops of distilled water are deposited at multiple positions on the PCL films and based on each water drop profile, the contact angle value is assessed using Laplace-Young curve fitting. For every condition in this work, the reported contact angle value is the average of 10 values measured on 2 different samples.

\section{b. X-ray photoelectron spectroscopy (XPS)}

To get an insight into the surface chemical composition, XPS measurements are done on the PCL films. The analysis is performed on a PHI 5000 Versaprobe II spectrometer equipped with a monochromatic $\mathrm{Al} \mathrm{K}$ X-ray source $(\mathrm{h} v=1486.6 \mathrm{Ev})$ at a power of $50 \mathrm{~W}$ (beam size $200 \mu \mathrm{m})$. The pressure in the analyzing chamber is maintained to at least $10^{-6} \mathrm{~Pa}$. A hemispherical analyzer detecting the photoelectrons, is placed at an angle of $45^{\circ}$ with respect to the PCL surface normal.

Survey scans, measuring 2 samples with 4 points per sample, are recorded with a pass energy of $187.85 \mathrm{eV}$ and are used to identify the elements present on the PCL surface. The element quantification is done via Multipack software (V 9.6) with a Shirley background by applying the relative sensitivity factors supplied by the manufacturer of the instrument. High-resolution $\mathrm{C} 1 \mathrm{~s}$ peaks are also recorded with a pass energy of $23.5 \mathrm{eV}$ and Multipak software is again used to curve fit these peaks. The energy scale is calibrated with respect to the hydrocarbon 
component of the C1s spectrum (285.0 ev). Afterwards, Gaussian-Lorentzian peak shapes (100$80 \%$ Gaussian) are utilized for the deconvolution of the peaks and the full-width at half maximum (FWHM) of each line shape is restricted below $1.6 \mathrm{eV}$.

\section{c. Atomic force microscopy (AFM)}

Besides the chemical characterization, physical properties are studied through the examination of PCL surface topography and roughness using an XE-70 atomic force microscope (Park Systems). A silicon cantilever (Nanosensors ${ }^{\mathrm{TM}}$ PPP -NCHR) scans the PCL surface in a noncontact mode. $15 \mu \mathrm{m}$ images are recorded and analyzed using XEP software after their modification with an $\mathrm{X}$ and Y plane auto-fit procedure. In this study, each roughness value is the average of 6 values measured on 2 different samples.

In order to determine the thickness of PCL films, a scratch is gently done on the film to locally remove it from the glass plate. AFM images covering the scratched and the unscratched areas on both sides, are recorded. XEP software is used to measure, without image flattening, the height difference between the two areas, which is the thickness of the film. The average of 10 measurements gives a thickness of $600.2 \mathrm{~nm}$ with a standard deviation of $13.3 \mathrm{~nm}$, thereby indicating that the films are uniform.

\section{Cell culture tests}

\section{a. Cell culture and cell seeding}

Adipose-derived stem cells (ADSCs) from male Wistar rat cadavers are cultured in DMEM Glutamax (Gibco ${ }^{\mathrm{TM}}$; Invitrogen) supplemented with 10\% foetal calf serum (FCS) and 1\% penicillin/streptomycin in a humidified atmosphere at $37^{\circ} \mathrm{C}$ and $5 \% \mathrm{CO}_{2}$. Cells are subcultured when reaching $80-90 \%$ confluence and the medium is changed every 3-4 days. ADSCs of passage 3 are seeded on either PCL films or on tissue culture plastic (TCP) in a 24-well plate. A density of 50000 cells/ $100 \mu \mathrm{l}$ per sample for adhesion tests and 20000 cells/100 $\mu 1$ per sample for proliferation tests is used. The cells are allowed to adhere for $4 \mathrm{~h}$ before adding more medium. Cell adhesion and proliferation are evaluated after $24 \mathrm{~h}$ and 7 days respectively.

\section{b. Live/dead staining ( $\mathrm{CaPi}$ ) and fluorescence microscopy}

Live/dead staining with calcein AM/propidium iodide is performed to evaluate cell viability, cell attachment and cell morphology. After rinsing the PCL films, the supernatant is replaced with $1 \mathrm{ml}$ phosphate buffered saline (PBS) supplemented with $2 \mu \mathrm{l}(1 \mathrm{mg} / \mathrm{ml})$ calcein AM (Anaspec; 89201) and $2 \mu 1(1 \mathrm{mg} / \mathrm{ml}$ ) propidium iodide (Sigma-Aldrich; P4170). After $10 \mathrm{~min}$ 
incubation in the dark at room temperature, samples are washed with PBS and evaluated with a fluorescence microscope (Olympus IX 81).

\section{c. MTT assay}

To quantify the amount of metabolically active ADSCs adhering and proliferating on the PCL films, a colorimetric assay based on the yellow tetrazolium dye 3-(4,5-dimethyldiazol-2-yl)-2,5diphenyltetrazolium bromide (MTT, Merck Promega) is performed. Briefly, cell culture medium is replaced by MTT solution ( $0.5 \mathrm{mg}$ MTT/ml medium) and cells are incubated for $4 \mathrm{~h}$ at $37^{\circ} \mathrm{C}$. Next, MTT solution is removed and lysis buffer $(1 \%$ Triton X-100 in isopropanol/0.4\% $\mathrm{HCl}$ ) is added for $30 \mathrm{~min}$ at $37^{\circ} \mathrm{C}$. Subsequently, $200 \mu \mathrm{l}$ of the dissolved formazan solution is transferred into a 96-well plate and measured at $580 \mathrm{~nm}$ with a spectrophotometer (Universal microplate reader EL 800, Biotek Instruments). Optical density of the PCL films is expressed as a ratio compared to TCP. All measurements are performed in triplicate.

To compare differences in adhesion and proliferation between plasma treatments and sterilization methods, one-way ANOVA followed by post-hoc Tukey (equal variances) or oneway ANOVA followed by post-hoc Dunnett's T3 (unequal variances) are performed using SPSS 23.0 software. Values of $\mathrm{p}<0.05$ are considered statistically significant.

\section{Results and Discussion}

The results of this paper are divided into two parts: the first part is dedicated to study the effect of the plasma treatment on the surface properties of PCL films while the second part mainly focuses on the effect of the sterilization on the properties of the plasma-treated films as well as on their bioactivity.

\section{Plasma treatment}

\section{a. Electrical characterization of the DBD discharge}

In order to evaluate the mode in which the DBD is operating, electrical properties of the different discharges are characterized. The voltage-current waveforms of the DBD operating in air and argon are visualized in Fig 2. For the air plasma treatment, the discharge current shows several spike-like pulses with nanosecond duration at certain sections of every half cycle of the applied voltage. Every current pulse corresponds to a series of microdischarges, clearly indicating that the DBD sustained in air operates in a filamentary mode ${ }^{34}$. Despite this non-uniform microdischarge activity, previous results showed a homogenous surface modification after 
plasma treatment ${ }^{19}$. For the argon discharge, at every half cycle of the voltage, only one wide peak is distinguished on the current waveform. This demonstrates that the argon discharge operates in a glow mode which guarantees a homogeneous treatment ${ }^{35}$.
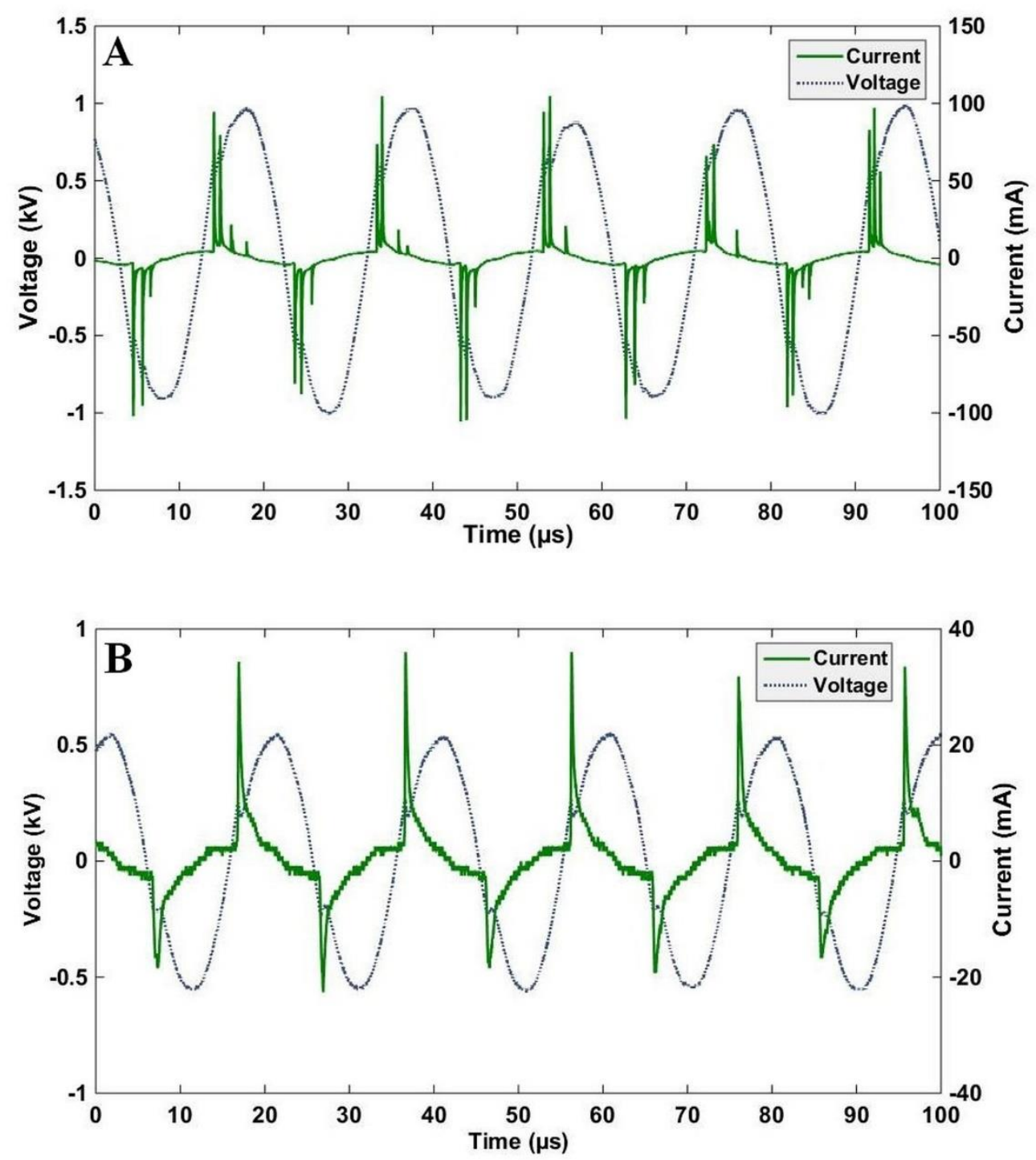

Fig. 2 Current-voltage waveforms of the DBD sustained in air (A) and argon (B)

\section{b. Water contact angle measurements}

Water contact angle measurements present a straightforward and highly sensitive technique to evaluate the wettability of the untreated PCL films and those subjected to air or argon plasma treatment. Since the discharge power and the plasma exposure time are different for both working gases, the evolution of WCA values is presented in function of energy density (Fig 3). This value is obtained by multiplying the discharge power by the plasma exposure time divided by the area of the electrodes. 


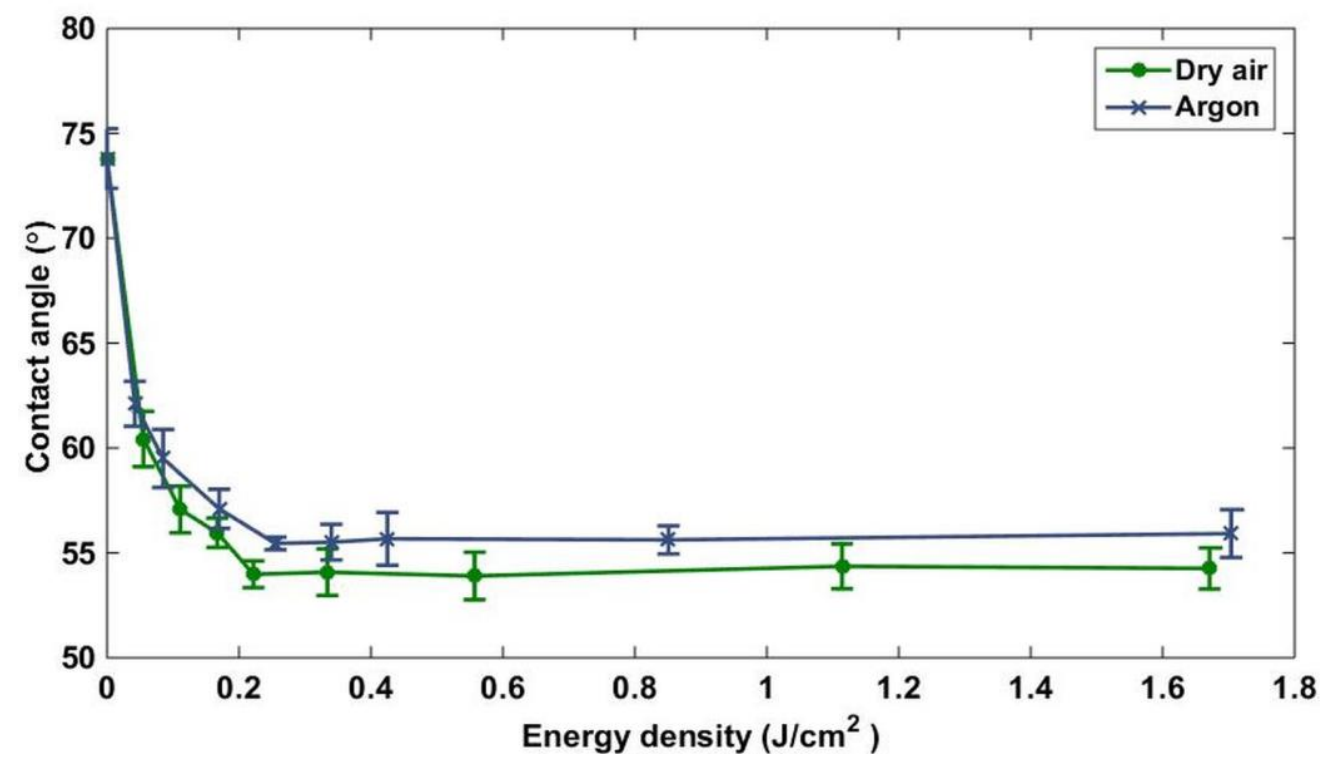

Fig. 3 Water contact angles as a function of energy density for air and argon plasma-treated PCL

At an energy density of 0 , corresponding to a non-exposure to plasma, the WCA of the PCL films is situated around $74^{\circ}$. When applying a plasma treatment, the WCA decreases, clearly showing an increased wettability due to the increased number of oxygen-containing groups incorporated on the surface ${ }^{7}$. A saturation of the treatment effect is observed at a certain energy density, above which the WCA does not decrease any further, suggesting that a longer plasma exposure does not provoke further surface chemical modifications. In the case of the argon plasma treatment, the lowest contact angle value of $55.5^{\circ}$ is obtained at an energy density of $0.25 \mathrm{~J} / \mathrm{cm}^{2}$, corresponding to a treatment time of $3 \mathrm{~s}$. For PCL samples treated in dry air, a plateau is reached for a slightly lower WCA value of $54^{\circ}$ at an energy density of $0.22 \mathrm{~J} / \mathrm{cm}^{2}$, which corresponds to a treatment time of $2 \mathrm{~s}$. Surprisingly, when the energy density is increased above $2 \mathrm{~J} / \mathrm{cm}^{2}$, this plateau is no longer maintained and the WCA decreases again progressively reaching a value of $42^{\circ}$ for an energy density of $26.75 \mathrm{~J} / \mathrm{cm}^{2}$ (Fig. 4). This decrease in WCA value at high energy densities is not observed for the argon treated samples as an almost unchanged value of $56^{\circ}$ is observed at an energy density of $25.55 \mathrm{~J} / \mathrm{cm}^{2}$. Air plasma treatment at high energy densities, is presumably causing a degradation of the PCL chemical structure observed trough XPS measurements, in line with the deterioration of the topographical and morphological surface characteristics examined via AFM imaging. These chemical and topographical changes are responsible for the extensive decrease in WCA value. For long plasma treatment times, many chain scissions occur, leading to polymer degradation. This phenomenon is reinforced in the presence of oxygen; that is why it is not seen in the case of 
argon treatment where oxygen is only present as impurity ${ }^{36}$. Moreover, air treatment is operating in a filamentary mode while argon treatment is operating in a glow mode. This results in the fact that at high energy densities, the local microdischarges of the filamentary air treatment, provoke strong local oxidations degrading the polymer resulting in etching that increases the surface roughness and thus lower the WCA value ${ }^{37-38}$. For argon treatments, a small decrease in WCA is detected at an energy density of $80 \mathrm{~J} / \mathrm{cm}^{2}$ and drastic changes in WCA begin to be observed only for energy densities above $100 \mathrm{~J} / \mathrm{cm}^{2}$. For example, a WCA of $27+/-$ $19.5^{\circ}$ is obtained at an energy density of $102.23 \mathrm{~J} / \mathrm{cm}^{2}$. The high standard deviations in these cases reveal the non-homogeneity of the polymer surface clearly indicating the degradation of the polymer.

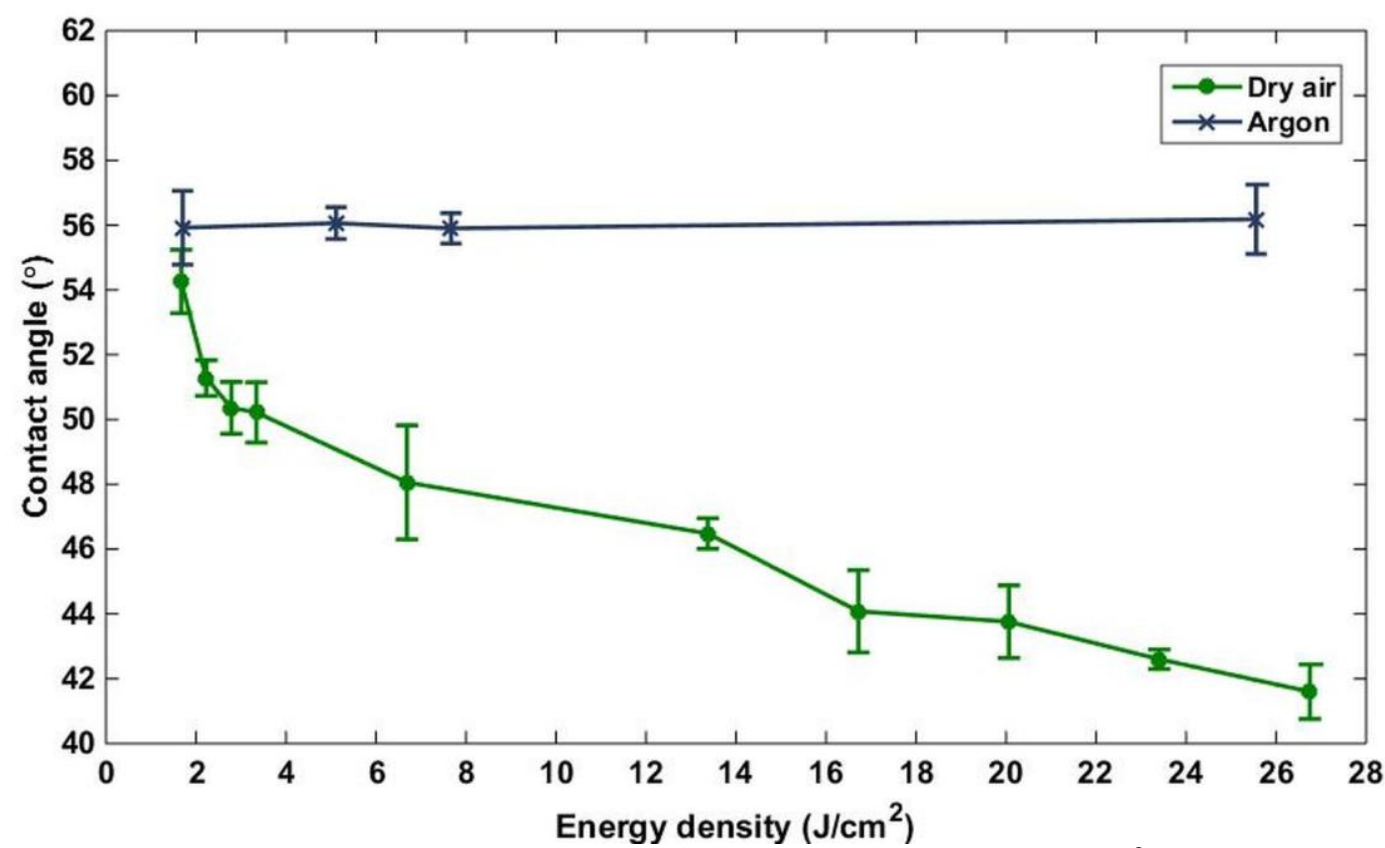

Fig. 4 Water contact angles as a function of energy densities above $1.6 \mathrm{~J} / \mathrm{cm}^{2}$ for air and argon plasma-treated PCL

It is well-known that polymers exhibit a hydrophobic recovery after plasma treatment because of the tendency of the surface to recover to its original untreated state ${ }^{39}$. This so-called ageing effect is mainly attributed to the reorientation of the incorporated polar groups towards the bulk of the material, in order to create an energetically stable state and adapt the surface chemical structure to the environment. The ageing effect is investigated in this study because of the time needed to subject the samples to a sterilization method. The longest sterilization method among the 3 studied methods, is the EtO sterilization which is a 2 day cycle sterilization, followed by an extra 2 days of aeration to reduce to the maximum the residual toxic EtO. Consequently, all 
the cell culture tests are done 4 days after the plasma treatment to ensure an objective comparison. Therefore it is important to find the plasma parameters resulting into a minimal ageing effect. After plasma treatment, the saturated air treated samples $\left(0.22 \mathrm{~J} / \mathrm{cm}^{2}\right)$ and argon treated samples $\left(0.25 \mathrm{~J} / \mathrm{cm}^{2}\right)$ are stored in ambient air at room temperature. The ageing behavior after 1 and 4 days is assessed by performing WCA measurements (Table 1). The WCA increases with ageing time and this increase is more pronounced for the air treated samples $\left(62^{\circ}\right.$ after 4 days) compared to the argon treated samples ( $58^{\circ}$ after 4 days). Morent et al. studied the ageing behavior of polypropylene, polyethylene terephthalate and PLA films and also found that the loss in treatment efficiency is higher for air than for argon treated samples ${ }^{40-41}$. This result can be explained by the different cross-linking degrees of the air and argon plasma-treated surfaces. It was shown that air plasma treatment highly oxidizes polymer surfaces with a low crosslinking degree. However, argon plasma treatment forms an oxidized highly cross-linked structure. The high cross-linking degree limits the number of mobile groups that can migrate or re-orientate from the PCL surface into the material bulk, thus limiting the ageing effect.

In a trial aimed to minimize the ageing effect, the energy density is increased by increasing the plasma exposure time to $10 \mathrm{~s}$, and the ageing behavior is then evaluated. Longer treatment times are not considered because of the risk of PCL degradation in the case of air plasma treatments. The increase in the plasma exposure time is shown beneficial for the air treated samples since a lower WCA $\left(58^{\circ}\right)$ is seen 4 days after the treatment of $10 \mathrm{~s}$, compared to the WCA $\left(62^{\circ}\right)$ obtained at a plasma exposure time of $2 \mathrm{~s}$. Most likely, longer treatment times exhibit a higher cross-linking degree.

An inverse effect is however observed for the argon treated samples as the WCA $\left(61^{\circ}\right) 4$ days after the treatment is higher for a plasma treatment of $10 \mathrm{~s} \mathrm{compared} \mathrm{to} \mathrm{a} \mathrm{plasma} \mathrm{treatment} \mathrm{of} 3$ $\mathrm{S}\left(58^{\circ}\right)$. Slepicka et al. modified high-density polyethylene and poly (tetrafluoro-ethylene) surfaces using an argon plasma treatment and also found that the ageing effect is less pronounced when the polymers are treated at the shortest exposure time ${ }^{42}$. This is presumably due to a higher relaxation of the polymer chains for longer argon plasma treatment times, leading to different mechanisms of oxygen group rotations from the polymer surface to the bulk. 
Table 1. Water contact angles as a function of ageing time for air and argon plasma-treated PCL at different plasma exposure times.

\begin{tabular}{cccccc}
\hline \multirow{2}{*}{ Treatment } & Plasma exposure & Energy density & \multicolumn{2}{c}{ WCA $\left(^{\circ}\right)$} \\
\cline { 4 - 6 } & time $(\mathrm{s})$ & $\left(\mathrm{J} / \mathrm{cm}^{2}\right)$ & 0 & Ageing time (days) & 4 \\
\hline \multirow{2}{*}{ Argon } & 3 & 0.25 & $55.4+/-0.3$ & $56.8+/-0.8$ & $58.3+/-1.0$ \\
& 10 & 0.85 & $55.6+/-0.7$ & $59.0+/-1.4$ & $60.6+/-0.5$ \\
\hline \multirow{2}{*}{ Air } & 2 & 0.22 & $54.0+/-0.6$ & $60.1+/-1.6$ & $62.0+/-0.6$ \\
& 10 & 1.11 & $54.4+/-1.0$ & $57.2+/-0.3$ & $58.5+/-0.8$ \\
\hline
\end{tabular}

Based on the obtained results, a $10 \mathrm{~s}$ air plasma exposure and a $3 \mathrm{~s}$ argon plasma exposure are used to treat the PCL films for the subsequent sterilization study. The ageing behavior of the PCL films treated with the abovementioned parameters is studied for a storage time of 14 days (Fig 5). The WCA increases with ageing time to reach a saturated value of almost $61^{\circ}$ and $63^{\circ}$ for the argon and air treated samples respectively. Despite increasing the plasma exposure time for the air treatment to minimize the ageing, the reached plateau value after approximately 9 days of ageing remains slightly higher compared to the argon treatment. However, the WCA values after 4 days of ageing are more or less the same for the air and argon plasma treatments $\left(58^{\circ}\right)$. It is important to highlight that these values remain considerably lower than the value of the untreated PCL film $\left(74^{\circ}\right)$ which means that a good wettability is maintained.

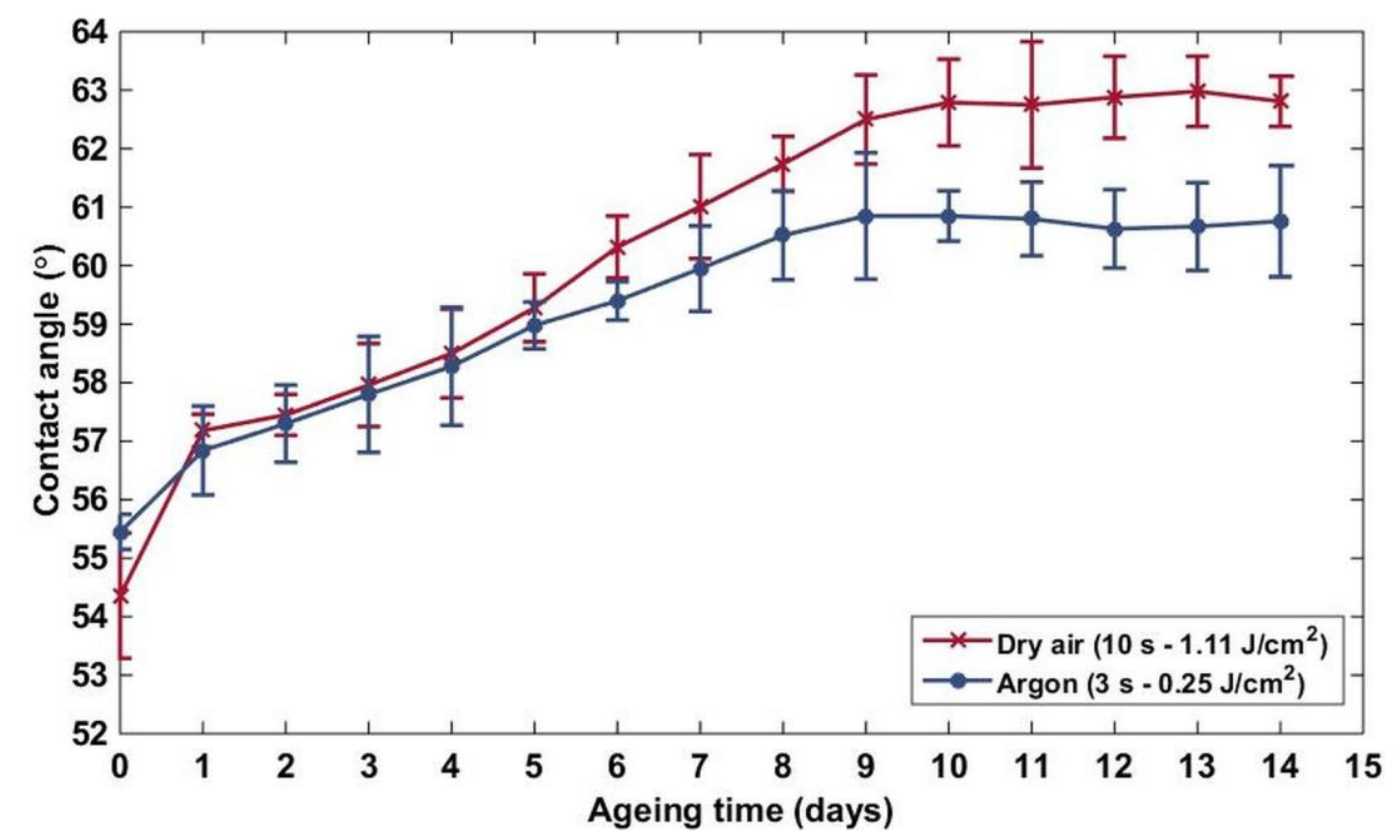

Fig. 5 Evolution of the water contact angle as a function of ageing time for air and argon plasmatreated PCL 


\section{c. XPS analysis}

In order to explain the increased wettability after plasma treatment, XPS measurements are performed and PCL surface chemistry is analyzed. The atomic composition is obtained from the survey spectra, while the different chemical bonds between carbon and oxygen are determined by the curve-fitting of the high-resolution $\mathrm{C} 1 \mathrm{~s}$ peaks, since each bond has a different binding energy. In accordance to the literature, the C1s envelope of the untreated PCL can be decomposed into 4 components: a peak at $285.0 \mathrm{eV}$ corresponding to hydrocarbon and carboncarbon bonds ( $\underline{\mathrm{C}}-\mathrm{C} / \underline{\mathrm{C}}-\mathrm{H})$, a peak at $285.5 \mathrm{eV}$ corresponding to a secondary carbon bonded to an ester group ( -COO), a peak at $286.5 \mathrm{eV}$ corresponding to a carbon single bonded to oxygen (C-O) and a peak at $289.1 \mathrm{eV}$ corresponding to a carboxyl or ester group $(\mathrm{O}-\underline{\mathrm{C}}=\mathrm{O}){ }^{43}$. Table 2 summarizes the obtained XPS results before and after plasma treatment at energy densities of $0.25 \mathrm{~J} / \mathrm{cm}^{2}$ and $0.22 \mathrm{~J} / \mathrm{cm}^{2}$, corresponding to the saturation point of argon and air treatments respectively. A schematic depiction of the curve fitting is observed in Fig 6. It is found that the carbon and oxygen content of the untreated PCL, together with the concentration of the different bonds, are in accordance with its chemical structure. After argon and air plasma treatment, the $\mathrm{O} / \mathrm{C}$ atomic ratio increases from 0.32 to 0.41 and 0.43 respectively, clearly indicating the presence of newly incorporated oxygen-containing groups. The increased oxygen content after argon treatment is attributed to the oxygen impurities remaining in the plasma chamber since it was not fully evacuated in addition to a post-oxidation. When taking a closer look at the surface chemical bonds, one can find that the concentration of the $\mathrm{C}-\mathrm{C}$ and $\mathrm{C}-\mathrm{H}$ bonds decreases while the concentration of the $\mathrm{C}-\mathrm{O}$ bonds increases. $\underline{\mathrm{C}}-\mathrm{COO}$ and $\mathrm{O}-\underline{\mathrm{C}}=\mathrm{O}$ bonds have, as expected, more or less the same concentration and tend to slightly increase after plasma treatment. Moreover, a new peak appears at $287.7 \mathrm{eV}$ corresponding to a carbon double bonded to oxygen $(\underline{\mathrm{C}}=\mathrm{O})$. These results suggest that air and argon plasma treatments mainly attack the $\mathrm{C}-\mathrm{C}$ and $\mathrm{C}$ $\mathrm{H}$ bonds and form oxygen-containing bonds responsible of the increased wettability of the PCL surfaces. More precisely, literature agrees that it is the non-reactive species present in the plasma that can break the C-C and C-H bonds and thus can lead to the formation of polymer radicals. These radicals can subsequently react with the chemically reactive species of the plasma, which incorporates new atoms on the polymer surface ${ }^{44}$. 
Table 2. Elemental composition and C1s curve fit results before and after plasma treatment

\begin{tabular}{|c|c|c|c|c|c|c|c|c|}
\hline \multirow[t]{3}{*}{ Treatment } & \multirow[t]{3}{*}{$\operatorname{WCA}\left({ }^{\circ}\right)$} & \multicolumn{2}{|c|}{ Atomic concentration $(\%)$} & \multicolumn{5}{|c|}{ C1s curve fit $(\%)$} \\
\hline & & $\mathrm{C}$ & $\mathrm{O}$ & $\underline{\mathrm{C}}-\mathrm{C} / \underline{\mathrm{C}}-\mathrm{H}$ & $\underline{\mathrm{C}}-\mathrm{COO}$ & $\underline{\mathrm{C}}-\mathrm{O}$ & $\underline{\mathrm{C}}=\mathrm{O}$ & $\mathrm{O}-\underline{\mathrm{C}}=\mathrm{O}$ \\
\hline & & & & $285.0 \mathrm{eV}$ & $285.5 \mathrm{eV}$ & $286.5 \mathrm{eV}$ & $287.7 \mathrm{eV}$ & $289.1 \mathrm{eV}$ \\
\hline No & $73.8+/-1.4$ & $75.7+/-0.6$ & $24.3+/-0.6$ & $58.2+/-0.5$ & $13.9+/-0.1$ & $14.3+/-0.3$ & 0 & $13.6+/-0.2$ \\
\hline $\begin{array}{c}\text { Argon } \\
\left(3 \mathrm{~s}-0.25 \mathrm{~J} / \mathrm{cm}^{2}\right)\end{array}$ & $55.4+/-0.3$ & $70.9+/-0.4$ & $29.1+/-0.4$ & $50.3+/-0.2$ & $14.4+/-0.6$ & $18.7+/-0.4$ & $1.9+/-0.3$ & $14.6+/-0.3$ \\
\hline $\begin{array}{c}\text { Air } \\
\left(2 \mathrm{~s}-0.22 \mathrm{~J} / \mathrm{cm}^{2}\right)\end{array}$ & $54.0+/-0.6$ & $69.8+/-0.5$ & $30.2+/-0.5$ & $49.1+/-0.8$ & $15.0+/-0.4$ & $17.9+/-1.0$ & $2.2+/-0.1$ & $15.9+/-0.4$ \\
\hline
\end{tabular}



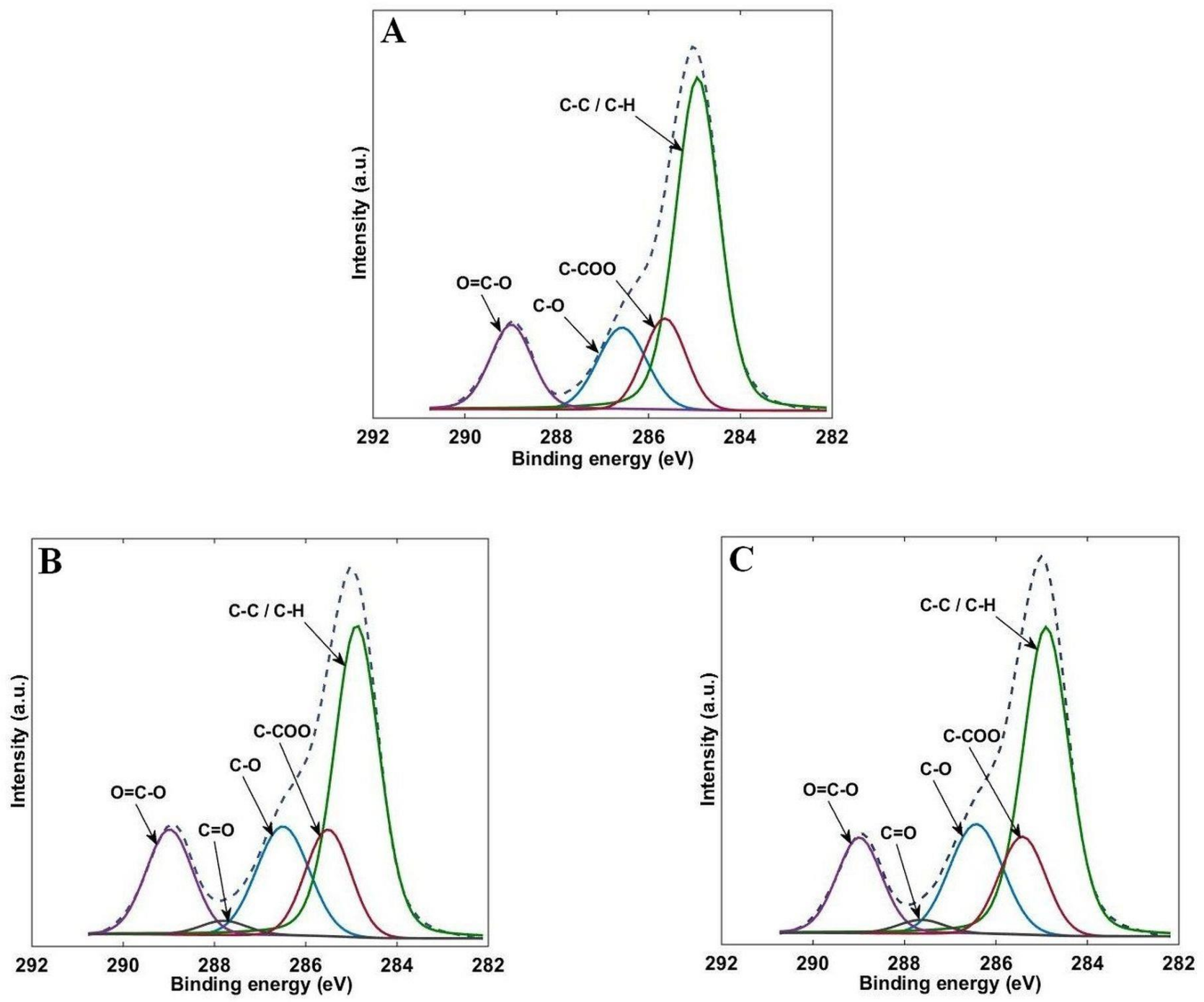

Fig 6. High-resolution C1s peak of the untreated (A), argon (B) and air (C) plasma-treated PCL To be able to understand the continuous decrease in WCA for long treatment times, observed in the case of air plasma treatment, the evolution of the surface chemistry in function of treatment time, is studied in this paragraph. For the air plasma-treated surfaces, plasma exposure times of $2 \mathrm{~s}$ and $10 \mathrm{~s}$, show more or less the same atomic composition as well as the same concentration of the different chemical bonds. This is attributed to a saturation effect resulting in the highest concentrations of new oxygen-containing groups formed on the PCL surface. No further chemical modifications are thus expected to take place, however, plasma exposure times of 30 $\mathrm{s}$ and above, cause a progressive decrease in carbon content and an increase in oxygen content. Concerning the surface chemical bonds, a progressive decrease in $\mathrm{C}-\mathrm{C}$ and $\mathrm{C}-\mathrm{H}$ bonds as well as a progressive increase in $\mathrm{C}=\mathrm{O}$ and $\mathrm{O}-\underline{\mathrm{C}}=\mathrm{O}$ bonds are clearly observed. Fig 7 A shows the high-resolution C1s peaks of PCL after air plasma exposure time of $240 \mathrm{~s}$. The increase in O- 
$\underline{\mathrm{C}}=\mathrm{O}$ concentration is accompanied with more or less unchanged $\underline{\mathrm{C}}-\mathrm{COO}$ concentration, which can be explained by a random scission of the chains, consistent with the increase of free $\mathrm{COOH}$ groups (Table 3). The increase in $\mathrm{C}=\mathrm{O}$ bonds and in free $\mathrm{COOH}$ groups is indicative of PCL degradation since it was observed by Domingos et al. when subjecting PCL to a degradation in basic solution ${ }^{45}$. Moreover, a PCL degradation was also observed when Pappa et al. treated PCL using air plasma at high power: $\mathrm{C}-\mathrm{C}$ bonds decreased and $\mathrm{C}=\mathrm{O}$ and $\mathrm{O}-\mathrm{C}=\mathrm{O}$ bonds increased significantly ${ }^{46}$. One can conclude that air plasma treatment at high exposure times is causing extensive chain scissions and thus degrading the polymer. The continuous decrease in WCA at high plasma exposure times is due to the increased oxygen content: the higher the oxygen concentration, the lower the WCA.

Table 3. Evolution of the WCA and XPS results in function of plasma exposure time for air plasma-treated PCL

\begin{tabular}{|c|c|c|c|c|c|c|c|c|c|}
\hline \multirow{3}{*}{$\begin{array}{l}\text { Plasma } \\
\text { exposure } \\
\text { time (s) }\end{array}$} & \multirow{3}{*}{$\begin{array}{l}\text { Energy } \\
\text { density } \\
\left(\mathrm{J} / \mathrm{cm}^{2}\right)\end{array}$} & \multirow[t]{3}{*}{$\mathrm{WCA}\left({ }^{\circ}\right)$} & \multicolumn{2}{|c|}{ Atomic concentration (\%) } & \multicolumn{5}{|c|}{$\mathrm{C} 1 \mathrm{~s}$ curve fit $(\%)$} \\
\hline & & & \multirow{2}{*}{$\mathrm{C}$} & \multirow{2}{*}{$\mathrm{O}$} & $\underline{\mathrm{C}}-\mathrm{C} / \underline{\mathrm{C}}-\mathrm{H}$ & $\underline{\mathrm{C}}-\mathrm{COO}$ & $\underline{\mathrm{C}}-\mathrm{O}$ & $\underline{\mathrm{C}}=\mathrm{O}$ & $\mathrm{O}-\underline{\mathrm{C}}=\mathrm{O}$ \\
\hline & & & & & $285.0 \mathrm{eV}$ & $285.5 \mathrm{eV}$ & $286.5 \mathrm{eV}$ & $287.7 \mathrm{eV}$ & $289.1 \mathrm{eV}$ \\
\hline 2 & 0.22 & $54.0+/-0.6$ & $69.8+/-0.5$ & $30.2+/-0.5$ & $49.1+/-0.8$ & $15.0+/-0.4$ & $17.9+/-1.0$ & $2.2+/-0.1$ & $15.9+/-0.4$ \\
\hline 10 & 1.11 & $54.4+/-1.1$ & $69.6+/-0.2$ & $30.4+/-0.2$ & $49.4+/-0.4$ & $15.4+/-0.8$ & $17.2+/-0.5$ & $1.9+/-0.3$ & $16.0+/-0.1$ \\
\hline 30 & 3.34 & $50.2+/-0.9$ & $67.6+/-0.2$ & $32.4+/-0.2$ & $47.3+/-0.2$ & $14.8+/-0.2$ & $18.0+/-0.5$ & $2.4+/-0.1$ & $17.5+/-0.4$ \\
\hline 60 & 6.69 & $47.9+/-1.1$ & $65.9+/-0.5$ & $34.1+/-0.5$ & $44.2+/-0.4$ & $14.8+/-0.7$ & $19.1+/-0.8$ & $2.8+/-0.3$ & $19.1+/-0.7$ \\
\hline 120 & 13.37 & $45.9+/-0.6$ & $64.2+/-0.1$ & $35.8+/-0.1$ & $43.2+/-0.2$ & $14.4+/-0.2$ & $19.1+/-0.4$ & $3.5+/-0.2$ & $19.8+/-0.3$ \\
\hline 240 & 26.75 & $42.6+/-0.3$ & $62.4+/-0.8$ & $37.6+/-0.8$ & $40.5+/-1.0$ & $13.1+/-0.8$ & $20.7+/-0.9$ & $3.1+/-0.3$ & $22.6+/-1.0$ \\
\hline
\end{tabular}

Increasing the plasma exposure time in the case of argon plasma treatment does not show the same effect. At a treatment time of 3,10,60 and $300 \mathrm{~s}$, the surface atomic composition and the concentration of the chemical bonds remain the same (Table 4). This observation is in correlation with the unchanged WCA value. The surface is saturated after an argon plasma treatment of $3 \mathrm{~s}$ and no degradation is observed at higher exposure time. Fig $7 \mathrm{~B}$ shows the highresolution C1s peaks of PCL after argon plasma exposure time of 300 s. As mentioned previously, it was shown that the presence of atomic oxygen enhances the polymer degradation 35. During argon plasma treatment, only a small percentage of oxygen is left in the plasma chamber, which can explain why the polymer is not degraded. 
Table 4. Evolution of the WCA and XPS results in function of the plasma exposure time for argon plasma-treated PCL

\begin{tabular}{|c|c|c|c|c|c|c|c|c|c|}
\hline \multirow{3}{*}{$\begin{array}{l}\text { Plasma } \\
\text { exposure } \\
\text { Time (s) }\end{array}$} & \multirow{3}{*}{$\begin{array}{l}\text { Energy } \\
\text { density } \\
\left(\mathrm{J} / \mathrm{cm}^{2}\right)\end{array}$} & \multirow[t]{3}{*}{$\mathrm{WCA}\left({ }^{\circ}\right)$} & \multicolumn{2}{|c|}{ Atomic concentration (\%) } & \multicolumn{5}{|c|}{$\mathrm{C} 1 \mathrm{~s}$ curve fit $(\%)$} \\
\hline & & & $\mathrm{C}$ & $\mathrm{O}$ & $\underline{\mathrm{C}}-\mathrm{C} / / \mathrm{-}-\mathrm{H}$ & $\underline{\mathrm{C}}-\mathrm{COO}$ & $\underline{\mathrm{C}}-\mathrm{O}$ & $\underline{\mathrm{C}}=\mathrm{O}$ & $\mathrm{O}-\underline{\mathrm{C}}=\mathrm{O}$ \\
\hline & & & & & $285.0 \mathrm{eV}$ & $285.5 \mathrm{eV}$ & $286.5 \mathrm{eV}$ & $287.7 \mathrm{eV}$ & $289.1 \mathrm{eV}$ \\
\hline 3 & 0.52 & $55.4+/-0.3$ & $70.9+/-0.4$ & $29.1+/-0.4$ & $50.3+/-0.2$ & $14.4+/-0.6$ & $18.7+/-0.4$ & $1.9+/-0.3$ & $14.6+/-0.3$ \\
\hline 10 & 0.85 & $55.6+/-0.7$ & $70.8+/-0.3$ & $29.2+/-0.3$ & $50.2+/-0.1$ & $15.1+/-0.3$ & $18.1+/-0.1$ & $2.3+/-0.1$ & $14.5+/-0.2$ \\
\hline 60 & 5.11 & $55.8+/-1.1$ & $70.7+/-0.9$ & $29.3+/-0.9$ & $50.9+/-0.4$ & $14.7+/-1.0$ & $18.1+/-0.2$ & $1.7+/-0.2$ & $14.6+/-0.5$ \\
\hline 300 & 25.55 & $56.1+/-1.1$ & $70.5+/-0.6$ & $29.5+/-0.6$ & $50.8+/-1.3$ & $14.6+/-1.2$ & $18.6+/-0.1$ & $2.0+/-0.1$ & $13.9+/-0.2$ \\
\hline
\end{tabular}
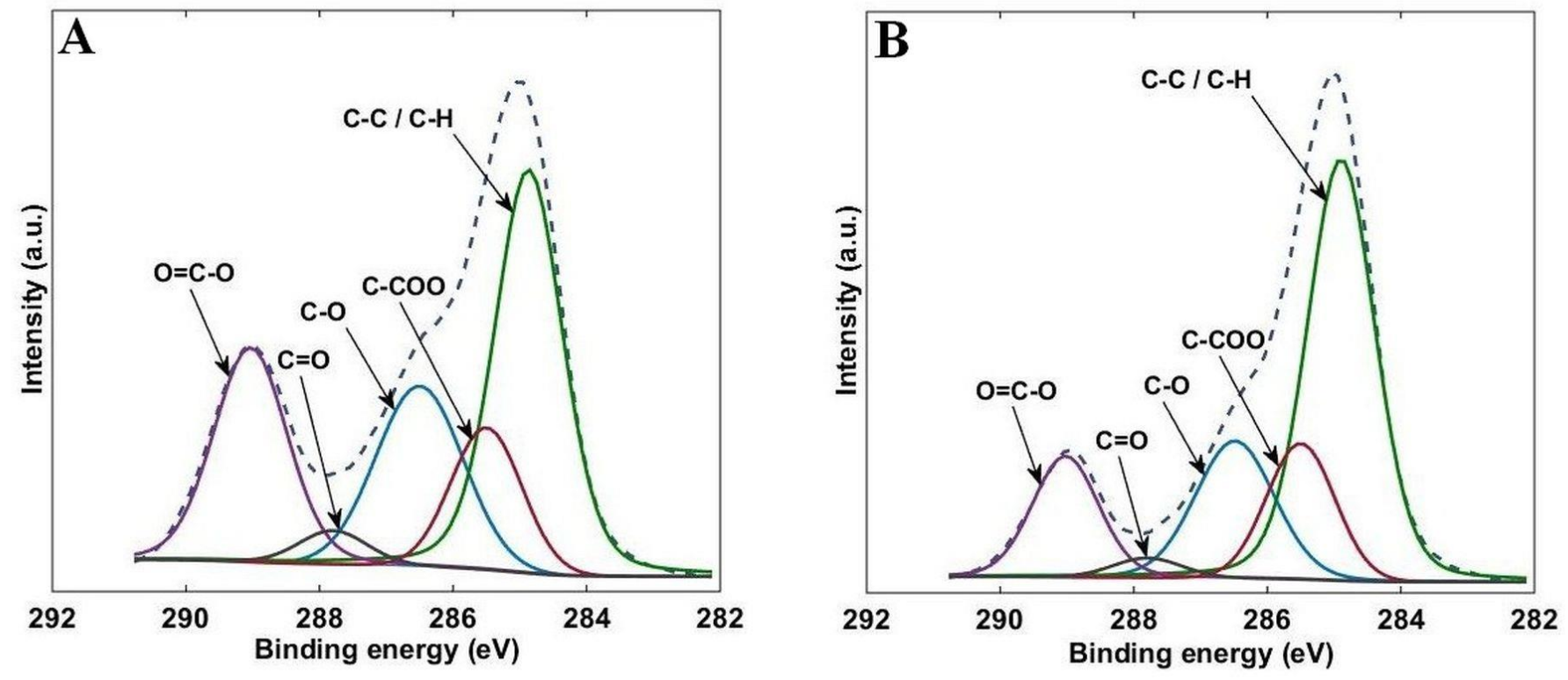

Fig 7. High-resolution C1s peaks of argon and air plasma-treated PCL. A: air (240 s - $26.75 \mathrm{~J} /$ $\left.\mathrm{cm}^{2}\right)$, B: $\operatorname{argon}\left(300 \mathrm{~s}-25.55 \mathrm{~J} / \mathrm{cm}^{2}\right)$

As all the measurements on the sterilized samples are done 4 days after the plasma treatment, it is necessary to execute an XPS analysis on non-sterilized and aged plasma-treated samples, to enable an accurate comparison. Therefore, PCL films subjected to $3 \mathrm{~s}$ argon or $10 \mathrm{~s}$ air plasma treatments are stored for 4 days in ambient air at room temperature, then XPS measurements are performed (Table 5). A decrease in $\mathrm{O} / \mathrm{C}$ ratio and slight decreases in the oxidized carbon bonds are observed, compared to the non-aged samples. These findings confirm that polar groups induced by the plasma activation, re-orientate and move away from the surface. Despite the observed decrease in $\mathrm{O} / \mathrm{C}$ ratio (0.38), it remains considerably higher than the $\mathrm{O} / \mathrm{C}$ ratio $(0.32)$ 
of the untreated PCL, meaning that a part of the oxygen induced during the plasma treatment is still on the surface.

Table 5. Elemental composition and C1s curve fit results of PCL samples 4 days after plasma treatment

\begin{tabular}{|c|c|c|c|c|c|c|c|c|}
\hline \multirow[t]{3}{*}{ Treatment } & \multirow[t]{3}{*}{$\mathrm{WCA}\left({ }^{\circ}\right)$} & \multicolumn{2}{|c|}{ Atomic concentration (\%) } & \multicolumn{5}{|c|}{$\mathrm{C} 1 \mathrm{~s}$ curve fit $(\%)$} \\
\hline & & $\mathrm{C}$ & $\mathrm{O}$ & $\underline{\mathrm{C}}-\mathrm{C} / \underline{\mathrm{C}}-\mathrm{H}$ & $\underline{\mathrm{C}}-\mathrm{COO}$ & $\underline{\mathrm{C}}-\mathrm{O}$ & $\underline{\mathrm{C}}=\mathrm{O}$ & $\mathrm{O}-\underline{\mathrm{C}}=\mathrm{O}$ \\
\hline & & & & $285.0 \mathrm{eV}$ & $285.5 \mathrm{eV}$ & $286.5 \mathrm{eV}$ & $287.7 \mathrm{eV}$ & $289.1 \mathrm{eV}$ \\
\hline $\begin{array}{c}\text { Argon } \\
\left(3 \mathrm{~s}-0.25 \mathrm{~J} / \mathrm{cm}^{2}\right)\end{array}$ & $58.3+/-1.0$ & $72.2+/-0.3$ & $27.8+/-0.3$ & $52.9+/-0.9$ & $14.1+/-0.7$ & $17.1+/-0.1$ & $1.4+/-0.3$ & $14.4+/-0.1$ \\
\hline $\begin{array}{c}\text { Air } \\
\left(10 \mathrm{~s}-1.11 \mathrm{~J} / \mathrm{cm}^{2}\right)\end{array}$ & $58.5+/-0.8$ & $72.0+/-0.6$ & $28.0+/-0.6$ & $51.9+/-1.1$ & $15.1+/-0.4$ & $17.3+/-0.7$ & $1.2+/-0.1$ & $14.4+/-0.3$ \\
\hline
\end{tabular}

\section{d. AFM imaging}

AFM measurements are performed on both untreated and plasma-treated films in order to visualize the morphology and to quantify the roughness of PCL surfaces. Fig 8 shows the AFM images of an untreated PCL film together with AFM images of air and argon plasma-treated films at different plasma exposure times. An unchanged PCL surface morphology is observed after air plasma exposure times of $2 \mathrm{~s}$ and $10 \mathrm{~s}$ and after argon plasma treatment. In contrast, extended air plasma exposure times significantly alter the morphology of the PCL surface and form microholes on it. This surface alteration is attributed to the PCL degradation which was already recognized in the WCA and XPS results. The root-mean-square roughness values quantifying the physical modifications, remain almost unchanged for the untreated, argon plasma-treated and air plasma-treated samples at short plasma exposure times. Increased roughness values are however detected for the PCL surfaces subjected to extended air plasma exposure (Table 6). The numerous chain scissions that occur at extended air plasma exposure lead to the formation of oligomers and desorption of volatile products from the PCL surface thus etching it. Literature agrees that oxygen mostly enhances this mechanism causing a pronounced etching effect ${ }^{44}$. Moreover, a comparison between glow and filamentary mode DBD plasmas shows that the filamentary mode, at high plasma power, provokes a more prominent etching damaging for example wool fibers, while the glow mode does not harm the same textile. The local microdischarges produced in the filamentary plasma treatment were found to cause strong local bombardments on studied fabric altering its surface ${ }^{37}$. This can explain the increased roughness and the modified morphology that are observed on the PCL samples only after air plasma treatment performed at high energy densities. 
Table 6. Root-mean-square roughness values of the untreated, air and argon plasma-treated PCL

\begin{tabular}{|c|c|c|c|}
\hline Treatment & Plasma exposure time(s) & Energy density $\left(\mathrm{J} / \mathrm{cm}^{2}\right)$ & Roughness (nm) \\
\hline No & 0 & 0 & $24.5+/-2.5$ \\
\hline \multirow{4}{*}{ Air } & 2 & 0.22 & $24.1+/-2.3$ \\
\hline & 10 & 1.11 & $24.5+/-2.8$ \\
\hline & 30 & 3.34 & $28.1+/-3.0$ \\
\hline & 60 & 6.69 & $30.7+/-3.5$ \\
\hline \multirow{2}{*}{ Argon } & 3 & 0.25 & $25.1+/-1.7$ \\
\hline & 60 & 5.11 & $24.0+/-2.7$ \\
\hline
\end{tabular}



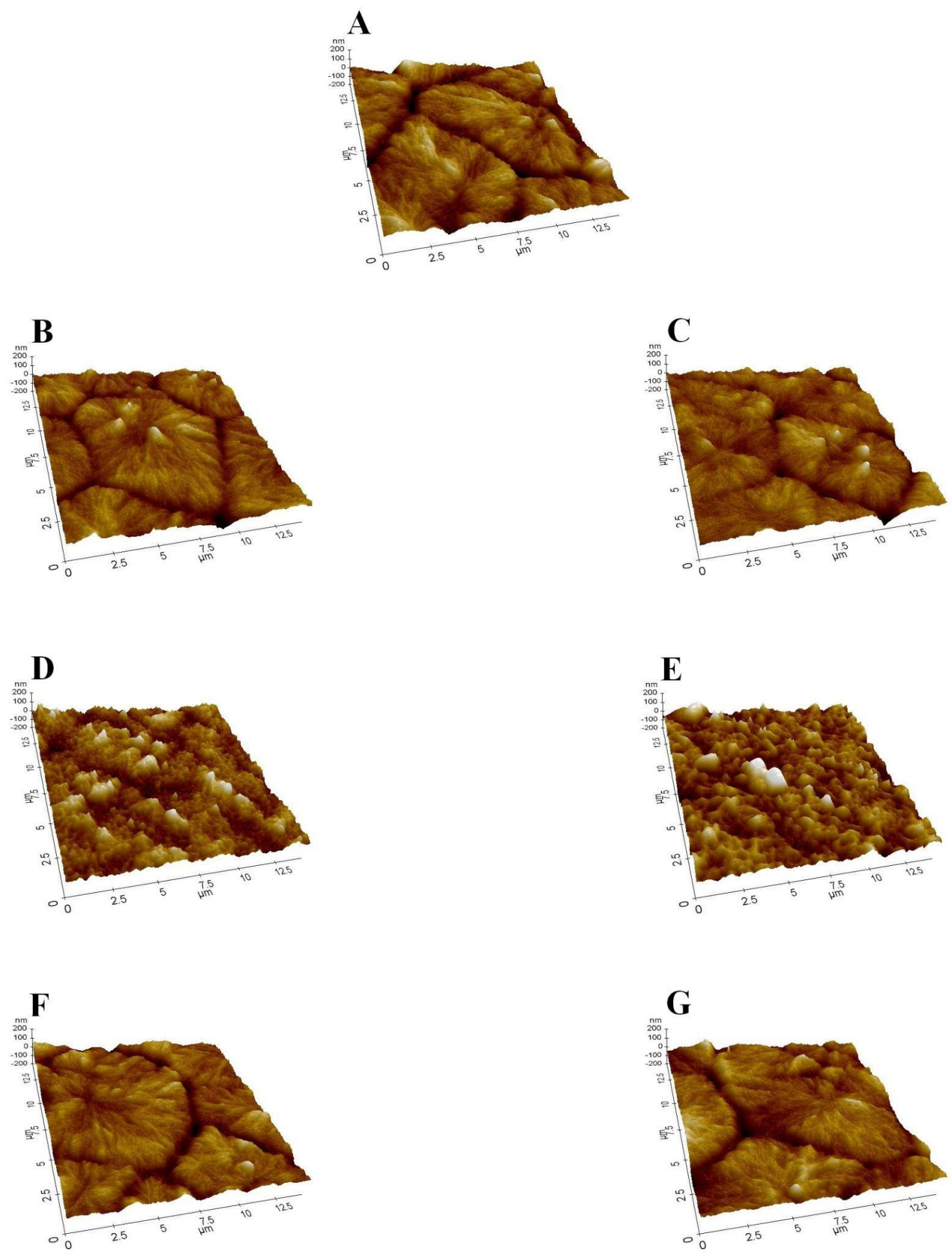

Fig 8. AFM images of untreated, air and argon plasma-treated PCL. A: Untreated, B: air (2 s $\left.0.22 \mathrm{~J} / \mathrm{cm}^{2}\right)$, C: $\operatorname{air}\left(10 \mathrm{~s}-1.11 \mathrm{~J} / \mathrm{cm}^{2}\right)$, D: air $\left(30 \mathrm{~s}-3.34 \mathrm{~J} / \mathrm{cm}^{2}\right), \mathrm{E}: \operatorname{air}\left(60 \mathrm{~s}-6.69 \mathrm{~J} / \mathrm{cm}^{2}\right), \mathrm{F}:$ $\operatorname{argon}\left(3 \mathrm{~s}-0.25 \mathrm{~J} / \mathrm{cm}^{2}\right), \mathrm{G}: \operatorname{argon}\left(60 \mathrm{~s}-5.11 \mathrm{~J} / \mathrm{cm}^{2}\right)$ 


\section{Sterilization}

\section{a. PCL sterility}

The potential of plasma treatment to serve as a sterilization method is evaluated by testing the sterility of PCL films treated at different plasma exposure times (Table 7). In order to allow a beneficial surface modification and to avoid the degradation of the polymer while aiming to sterilize it, a limited range of plasma treatment times is considered. For argon plasma treatment, 5 treatment times ranging between 3 and $900 \mathrm{~s}$ are studied while for air treatment, 2 treatment times of $2 \mathrm{~s}$ and $10 \mathrm{~s}$ are evaluated. The aforementioned results revealed that higher treatment times exhibit a degradation of the PCL films.

Table 7. Sterility of PCL films subjected to plasma, EtO, HP and UV treatments

\begin{tabular}{|c|c|c|c|}
\hline Sterilization treatment & Plasma exposure time (s) & Energy density $\left(\mathrm{J} / \mathrm{cm}^{2}\right)$ & $\%$ Sterility $(n=10)$ \\
\hline \multirow{2}{*}{ Air plasma } & 2 & 0.22 & 30 \\
\hline & 10 & 1.11 & 60 \\
\hline \multirow{5}{*}{ Argon plasma } & 3 & 0.25 & 40 \\
\hline & 60 & 5.11 & 70 \\
\hline & 300 & 25.55 & 80 \\
\hline & 600 & 51.11 & 90 \\
\hline & 900 & 76.67 & 80 \\
\hline EtO & & & 100 \\
\hline HP & & & 100 \\
\hline UV $1 \mathrm{~h}$ & & & 50 \\
\hline UV $2 h$ & & & 80 \\
\hline UV $3 \mathrm{~h}$ & & & 100 \\
\hline
\end{tabular}

Results show that the percentage of sterility increases with increasing plasma exposure time. This can be explained by the prolonged time needed for the plasma to sterilize PCL films, since, as already mentioned in the introduction, 3 phases are involved: destruction of the genetic material by the UV irradiation generated by the plasma, erosion of the microorganisms by photon-induced desorption and etching in presence of oxygen. Moreover, the UV dose is proportional to the exposure time. Argon treatment shows that at some point, increasing the treatment time becomes inefficient: $80 \%$ sterility after 300 and $900 \mathrm{~s}$ and $90 \%$ after $600 \mathrm{~s}$. This is probably due to the limited etching effect of the argon treatment. It was demonstrated that this effect erodes the microorganism surface and thus facilitates the passage of UV photons through it, allowing them to reach and destroy the DNA ${ }^{47}$. As a consequence, the studied argon treatment times fail to attain $100 \%$ sterility, and thus to sterilize PCL films. Air treatment shows 
the same result because of the short treatment times studied. For that reason, the sterilization of the PCL samples after plasma treatment becomes an unavoidable step. Three sterilization methods are adopted: UV, EtO and HP. PCL films are tested for their sterility after being subjected to these sterilizations (Table 7). Sterility is $100 \%$ achieved after HP and EtO sterilizations. Concerning the UV sterilization, different exposure times are tested and it is found that $100 \%$ sterility is reached after 3 hours. Therefore, plasma-treated films are sterilized by EtO, HP or $3 \mathrm{~h} \mathrm{UV}$ irradiation immediately after plasma treatment. Surface characterization and cell tests are performed 4 days after the sterilization, to keep the results accurately comparable. In the following experiments, plasma exposure times of $3 \mathrm{~s}$ and $10 \mathrm{~s}$ are adopted for argon and air treatments respectively, as previously mentioned.

\section{b. Water contact angle measurements}

Fig 9 shows the WCA results of untreated, air and argon plasma-treated samples before and after the 3 different sterilization methods.

After EtO sterilization, the WCA increases from around $74^{\circ}$ to $77^{\circ}$ for the untreated samples, and from $58^{\circ}$ to $65^{\circ}$ for air and argon plasma-treated samples. Peniston et al. also found a slight increase in WCA of PLA subjected to an EtO sterilization. The decreased wettability is presumably due to the modification of the PCL chain ends reacting with the EtO molecules. The short and strained C-C bonds of the EtO molecule can cause an easy opening of the ring, thus making it very reactive. Therefore, the following reactions between $\mathrm{EtO}$ and $\mathrm{COOH}$ or $\mathrm{C}-\mathrm{OH}$ end chains can occur:

\section{$\mathrm{CH}_{2} \mathrm{CH}_{2} \mathrm{O}+\mathrm{R}-\mathrm{COOH} \longrightarrow \mathrm{R}-\mathrm{COO}-\mathrm{CH}_{2} \mathrm{CH}_{2} \mathrm{OH}$ \\ $\mathrm{CH}_{2} \mathrm{CH}_{2} \mathrm{O}+\mathrm{R}-\mathrm{OH} \longrightarrow \mathrm{R}-\mathrm{O}-\mathrm{CH}_{2} \mathrm{CH}_{2} \mathrm{OH}$

The obtained structure from the reaction with the carboxylic group, is shielding this highly polar bond while exposing a hydroxyl group. This phenomenon is contributing to a more hydrophobic surface since $\mathrm{C}-\mathrm{OOH}$ bonds were shown to be more hydrophilic than $\mathrm{C}-\mathrm{O}$ bonds. The termination entity of the structure resulting from the reaction with the hydroxyl group is also a hydroxyl group, thus this reaction does not change the surface hydrophilicity ${ }^{31}$.

The increase in WCA is more pronounced for the plasma-treated samples. This can be explained by the fact that the plasma-treated surfaces contain more carboxyl group end chains so more $\mathrm{C}$ $\mathrm{OOH}$ bonds are shielded. 
HP sterilization causes a slight decrease in WCA of the untreated samples from around $74^{\circ}$ to $70^{\circ}$. Several studies also showed an increased WCA of polymeric materials after HP sterilization $31,48-49$. This is due to a surface oxidation adding polar groups to the surface and thus increasing its wettability. The oxidation occurs during the chemical phase corresponding to the exposure to the highly reactive $\mathrm{H}_{2} \mathrm{O}_{2}$ and during the plasma phase. However, it is believed that most of the surface modifications are produced during the chemical phase because the plastic bag wrapping the samples limits the number of plasma active species to reach the PCL surface ${ }^{48}$. This can explain why the observed decrease in WCA is relatively small after HP sterilization.

HP sterilization of the air and argon plasma-treated samples causes however an increase in WCA value from around $58^{\circ}$ to $68^{\circ}$. The results are indicative of a decreased wettability due to a depletion of hydrophilic chemical groups. One of the complex chemical alterations provoked by the highly reactive $\mathrm{H}_{2} \mathrm{O}_{2}$ and the plasma active species is presumably the scission of the polar bonds generated in the previous air and argon plasma activation.

After UV sterilization, the WCA remains constant for both untreated and plasma-treated samples, demonstrating that a UV exposure of $3 \mathrm{~h}$ does not provoke surface chemical modifications. XPS results, showed in the following paragraph, confirm this finding.

For all sterilization methods, no significant differences in WCA values are observed between the air and the argon plasma-treated samples.

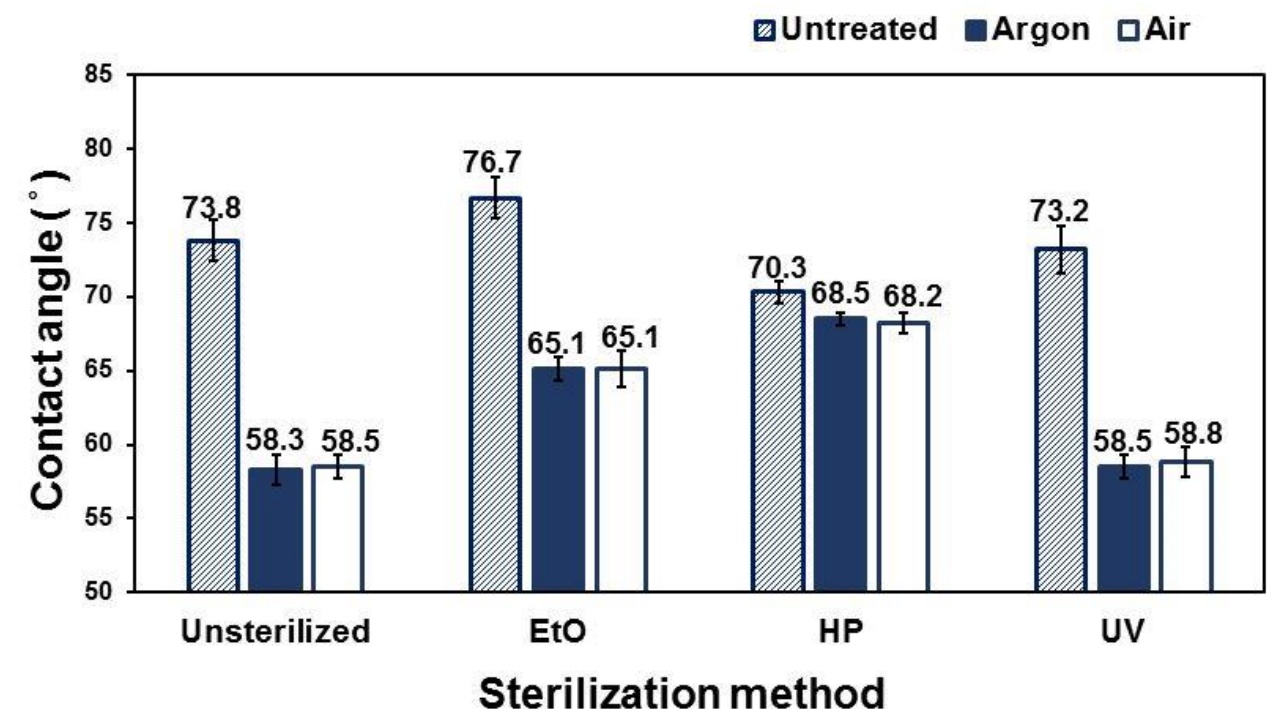

Fig 9. Water contact angles of untreated, air and argon plasma-treated PCL before and after EtO, HP and UV sterilizations 


\section{c. XPS analysis}

XPS analysis is performed on the untreated, air and argon plasma-treated samples before and after the 3 different sterilization methods, in order to investigate the changes in surface chemical composition induced by these sterilizations. Fig 10 and Fig 11 show the results obtained from the survey spectra and from the curve-fitting of the high-resolution $\mathrm{C} 1 \mathrm{~s}$ peaks respectively.

No significant changes in atomic composition and in the concentrations of the different chemical bonds are detected after EtO sterilization, whereas WCA measurements revealed a decreased wettability due to the reaction with EtO molecules modifying the chain ends of PCL. This can be explained by the limited ability of the EtO to penetrate into the polymer. EtO molecules react only with the top layers of PCL, knowing that WCA and XPS techniques have different depth of analysis: WCA is affected by the first atomic layers while XPS has a deeper penetration $(\approx$ $10 \mathrm{~nm})$.

After HP sterilization, a slight increase in oxygen content of the untreated samples is observed, while a decreased oxygen content is detected in the case of argon and air plasma-treated samples. These findings are in accordance with the WCA results. The oxidation of the untreated samples occurring during the chemical $\mathrm{H}_{2} \mathrm{O}_{2}$ phase and the plasma phase is confirmed by a decrease in the $\mathrm{C}-\mathrm{C} / \mathrm{C}-\mathrm{H}$ bonds accompanied by a slight increase in the concentration of $\mathrm{C}-\mathrm{O}$ groups as well as a small incorporation of $\mathrm{C}=\mathrm{O}$ groups. $\mathrm{H}_{2} \mathrm{O}_{2}$ is thus revealed to exhibit a better penetration compared to EtO. It is qualified to have a moderate-to-good penetration being able to penetrate as great as $1 \mathrm{~mm}$ in various plastics. ${ }^{49}$ An inverse effect is observed for the plasmatreated samples, where the concentration of $\mathrm{C}-\mathrm{C} / \mathrm{C}-\mathrm{H}$ bonds increases while slight decreases in $\mathrm{C}-\mathrm{O}, \mathrm{O}-\mathrm{C}=\mathrm{O}$ and $\mathrm{C}=\mathrm{O}$ groups are detected. This observation supports the suggestion stating that one of the chemical processes occurring during HP sterilization is the scission of the weak oxygen-containing bonds induced by the previous plasma treatment.

XPS results show that a UV exposure of 3 hours does not cause any chemical alteration of the untreated, argon and air plasma-treated samples, and this finding is in correlation with the unchanged WCA.

It is also important to mention that the surface chemical composition of argon and air plasmatreated samples after each sterilization method is nearly identical, which is in agreement with the WCA results described in the previous paragraph. 


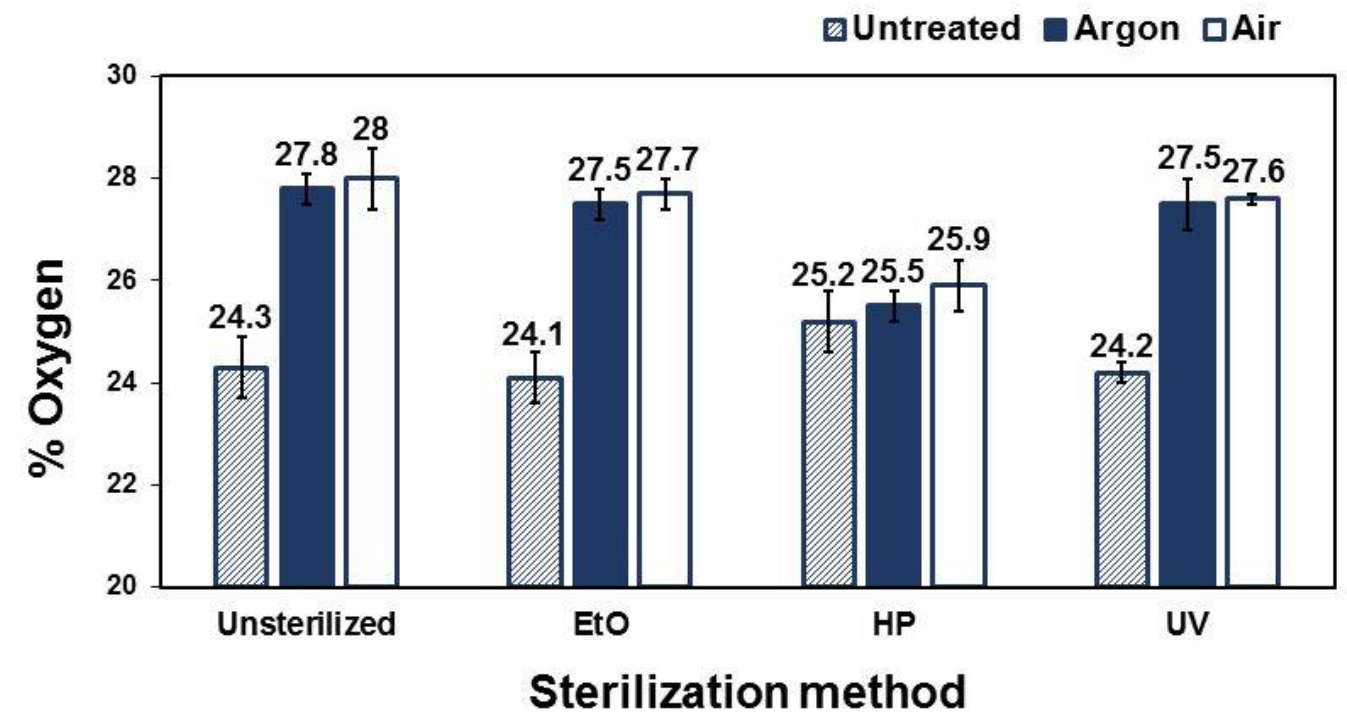

Fig 10. Surface oxygen content of untreated, air and argon plasma-treated PCL before and after EtO, HP and UV sterilizations 


\section{Untreated}
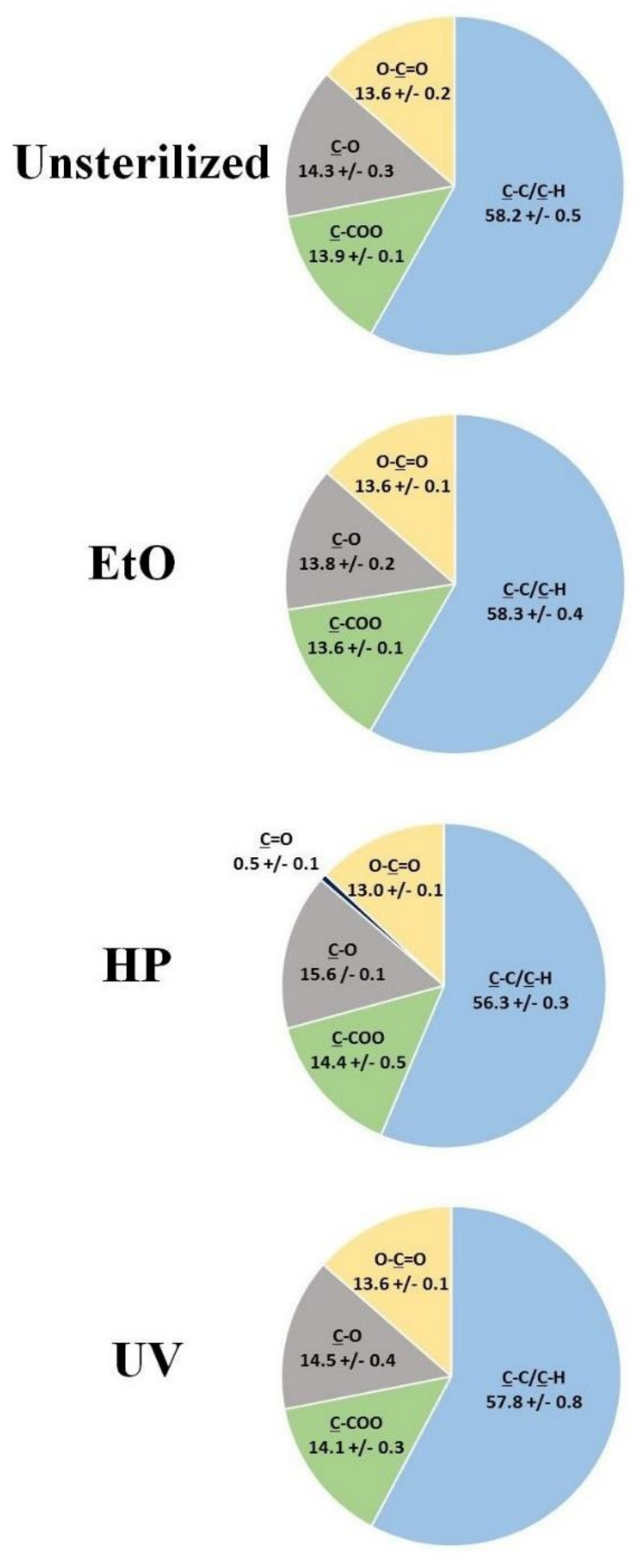

Argon
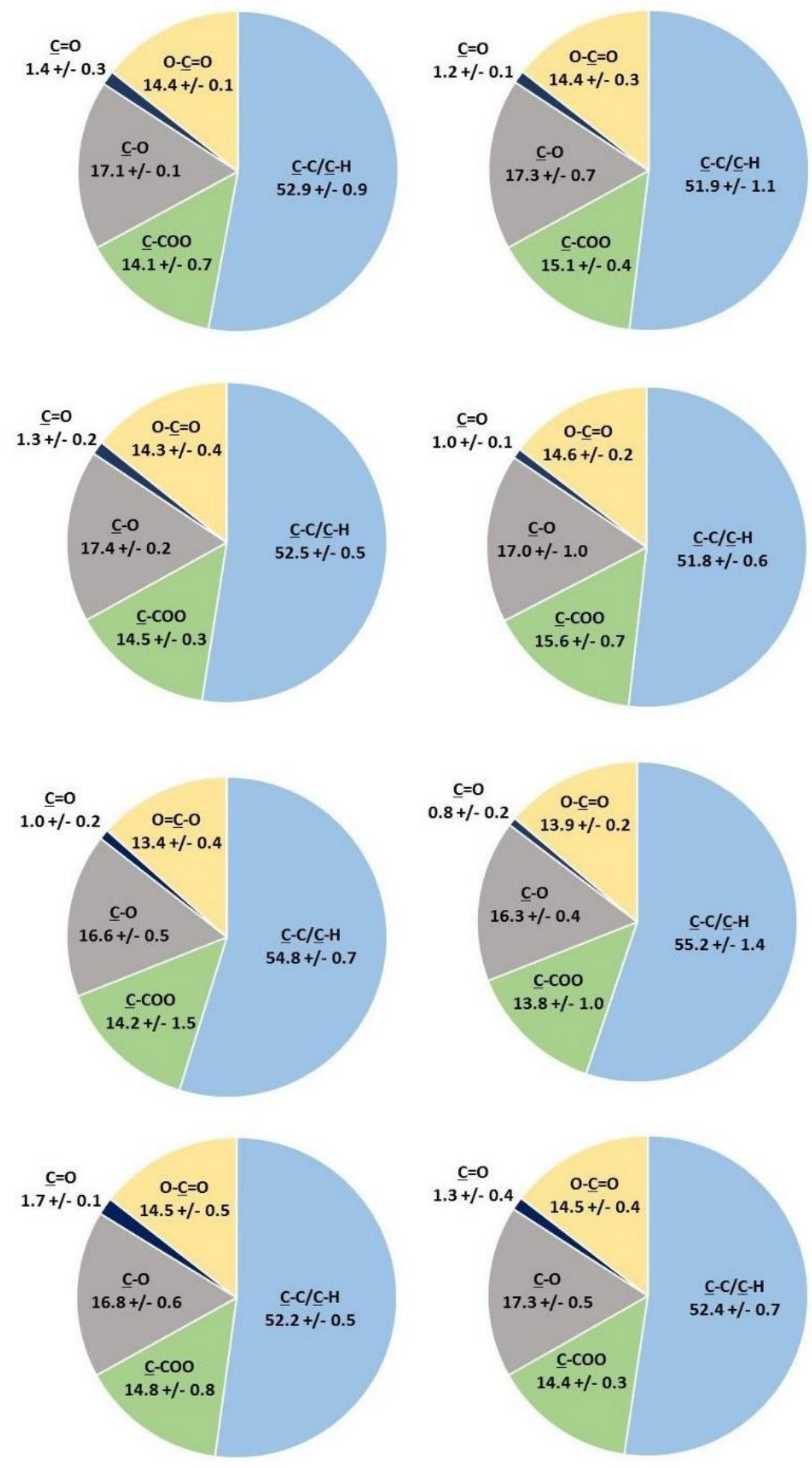

$=\mathrm{C}-\mathrm{C} / \mathrm{C}-\mathrm{H}=\mathrm{C}-\mathrm{COO}$
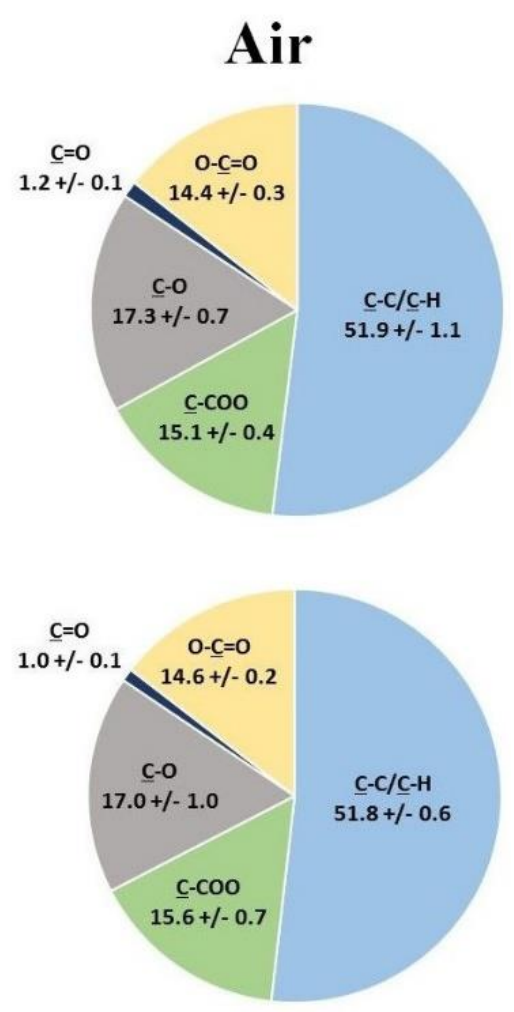

$\mathrm{C}-\mathrm{O} \| \mathrm{C}=\mathrm{O} \approx \mathrm{O}-\mathrm{C}=\mathrm{O}$

Fig 11. C1 curve fit results of untreated, air and argon plasma-treated PCL before and after EtO, HP and UV sterilizations 


\section{d.AFM imaging}

Surface physical properties of untreated, air and argon plasma-treated samples before and after the 3 sterilizations are examined via AFM imaging. Table 9 contains the obtained root-meansquare roughness values, while Fig 12 shows the acquired AFM images.

EtO sterilization does not alter the morphology of the untreated, argon and air plasma-treated samples. Moreover, no significant differences in roughness values are observed before and after the sterilization. Therefore, EtO is shown to preserve the surface topography and structural integrity of the films.

HP sterilization is however causing drastic changes to the surface morphology of the PCL films as seen in Fig 12. Lerouge et al. also showed certain alterations in the surface appearance and topography of polymeric medical devices subjected to HP sterilization ${ }^{48}$. These surface modifications suggest a surface erosion by the highly reactive $\mathrm{H}_{2} \mathrm{O}_{2}$ molecules followed by a surface etching induced during the plasma phase. The roughness increases after HP sterilization and reaches average values of 31.7, 36.3 and $39.4 \mathrm{~nm}$ for the untreated, argon and air plasmatreated samples respectively. Higher roughness values are thus observed in the case of plasmatreated samples. This is probably due to additional chain scissions of the polar bonds generated during the previous plasma treatments, leading to the formation of more volatile compounds and thus to a greater surface etching. Moreover, plasma treatments are weakening PCL surfaces which as a result become more fragile and thus prone to supplementary alterations when subjected to HP sterilization. Particularly, air plasma-treated samples are extensively damaged after HP sterilization resulting in non-homogenous surfaces with roughness values ranging between 20 to $65 \mathrm{~nm}$. This phenomenon can be explained by the fact that air plasma treatment, unlike the argon treatment, is operating in a filamentary mode giving cause to strong local microdischarges bombarding PCL surface non-homogenously and thus creating weak local spots.

An exposure to UV irradiation of $3 \mathrm{~h}$ does not provoke morphological and topographical modifications to the PCL surfaces. No significant changes in surface roughness values of untreated, air and argon plasma-treated PCL samples are detected. Fischbach et al. also observed no changes in surface roughness of PLA films subjected to $2 \mathrm{~h}$ of UV irradiation, however after extended exposure times a smoothening of the surface was noticed ${ }^{33}$. 
Table 9. Root-mean-square roughness values (in $\mathrm{nm}$ ) of untreated, air and argon plasmatreated samples before and after EtO, HP and UV sterilizations

\begin{tabular}{lccc}
\hline Treatment & Untreated & Argon & Air \\
\hline Unsterilized & $24.5+/-2.5$ & $25.1+/-1.7$ & $24.5+/-2.8$ \\
EtO & $24.1+/-3.7$ & $23.4+/-1.7$ & $22.7+/-2.3$ \\
HP & $31.7+/-2.1$ & $36.3+/-1.8$ & $39.4+/-14.1$ \\
UV & $23.8+/-2.0$ & $23.7+/-2.7$ & $25.3+/-2.3$ \\
\hline
\end{tabular}



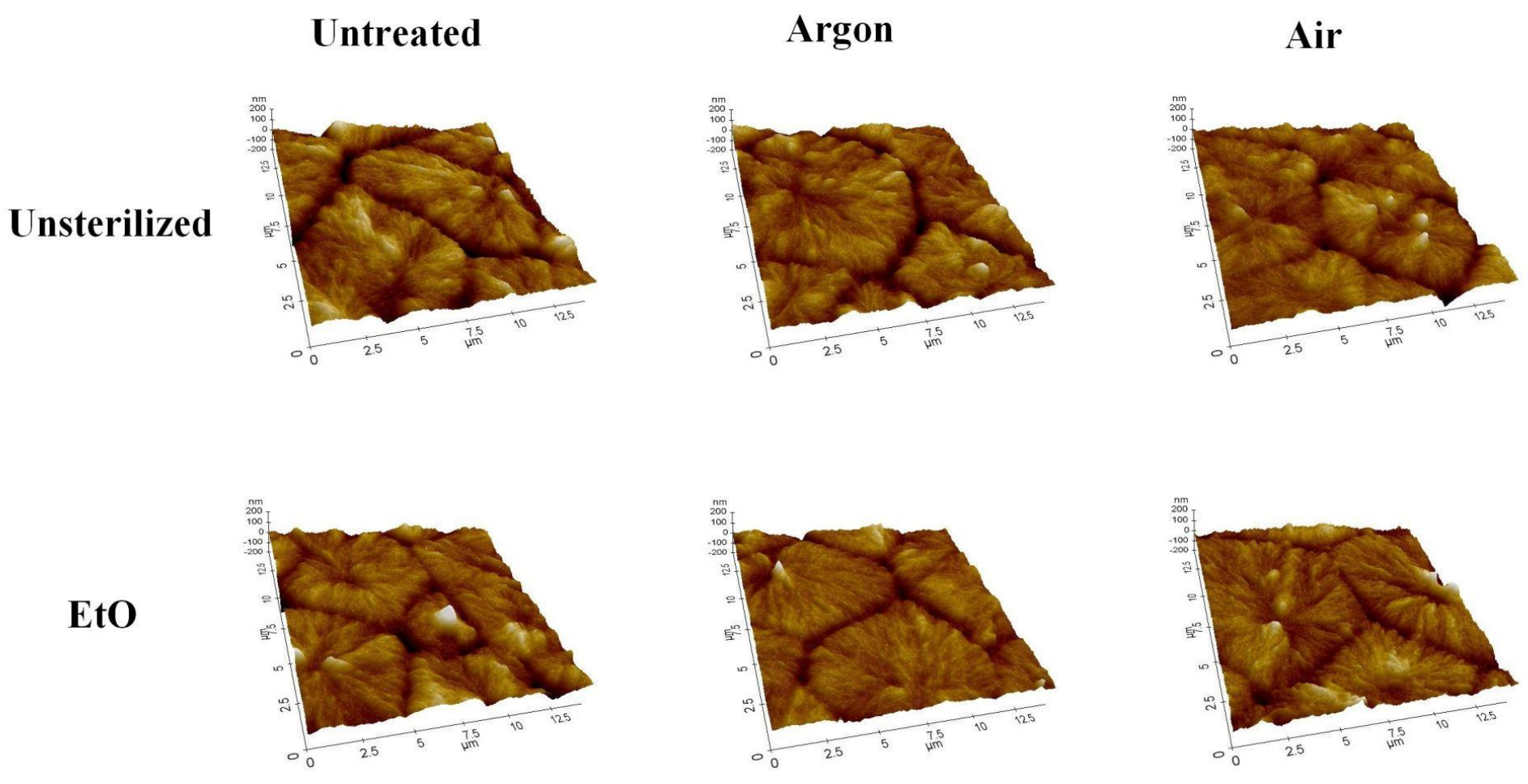

HP
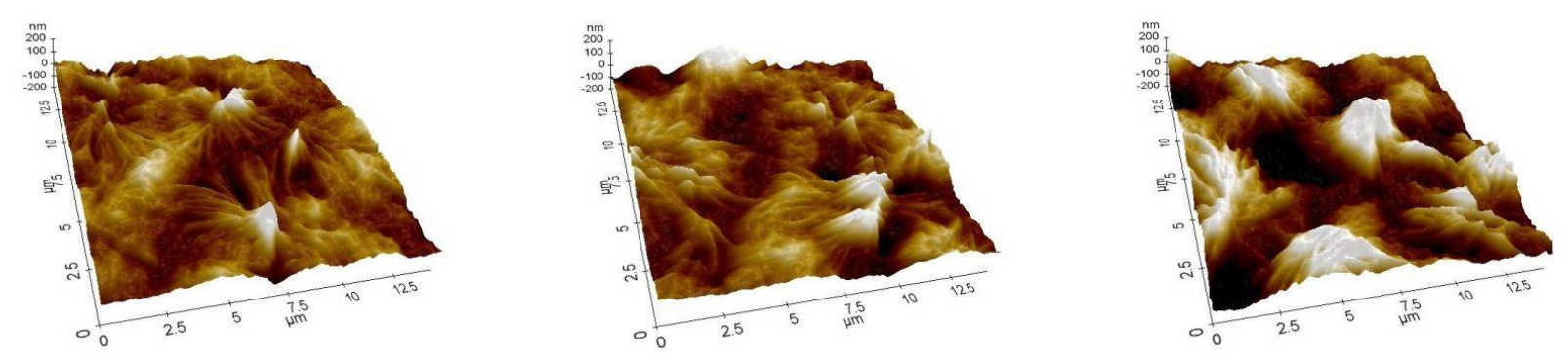

UV
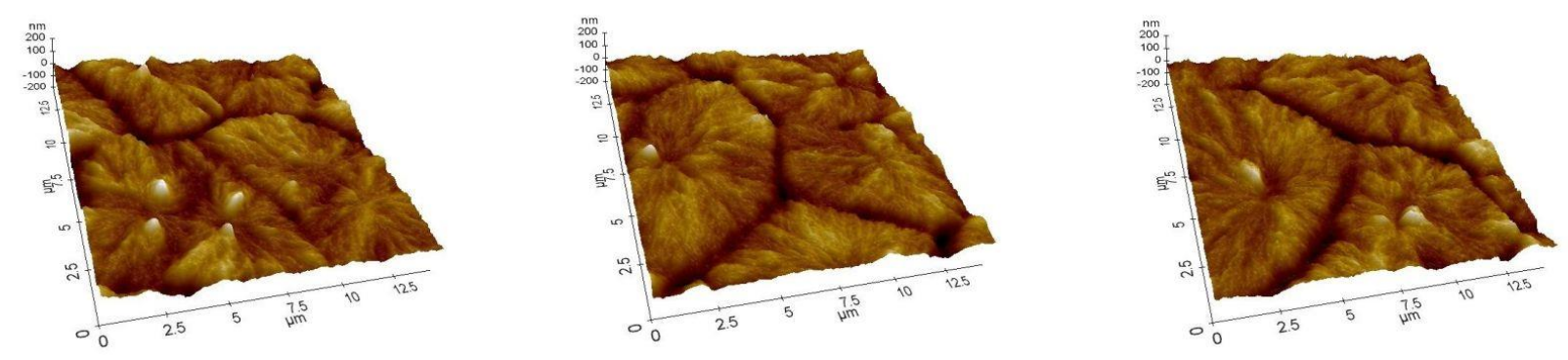

Fig 12. AFM images of untreated, air and argon plasma-treated PCL before and after EtO, HP and UV sterilizations 


\section{e. Adhesion, proliferation and morphology of ADSCs}

It is well known that cell-material interactions are largely influenced by the chemical and topographical features of the material surface. Thus, the ultimate goal of plasma treatment is the improvement of PCL surface properties to favor the cellular performance. In order to validate the effect of the plasma surface modification and evaluate the influence of the different sterilizations on the PCL bioactivity, cell culture tests are performed using ADSCs. Both after $24 \mathrm{~h}$ and 7 days, the overall cell number is higher on plasma-treated samples as evaluated by MTT assay, regardless of the sterilization method (Fig 13). These results are confirmed by the live/dead staining, showing a significantly greater cell attachment on plasma-treated samples compared to the untreated ones. Moreover, the ADSCs attached on plasma-treated surfaces exhibit an elongated morphology indicating a relative strong attachment and spreading, while the cells on the untreated surfaces are round which is a sign of poor attachment (Fig 14 and 15) ${ }^{50}$. This difference can be explained by the higher amount of oxygen-containing functionalities on the plasma-treated samples leading to an increased wettability promoting the protein adsorption and thus the initial cell attachment. Furthermore, oxygen-containing groups are correlated with an enhanced cellular growth, as reported in literature ${ }^{16}$.

For the untreated samples, however, there are important differences between sterilization methods. There is a significantly higher attachment and proliferation of ADSCs after HP sterilization compared to EtO and UV sterilization, almost reaching the level of tissue culture plastic. The roughness of the untreated samples increases after HP sterilization, leading to a closer mimicking of the nanoarchitecture of natural extracellular matrix and thus favoring, together with the slightly increased wettability, the cell attachment and proliferation ${ }^{51}$.

The effect of the sterilization methods is slightly different on plasma-treated samples. Attachment on both argon and air plasma-treated PCL films is higher after EtO and UV sterilization compared to HP sterilization. This can again be correlated to the wettability of the samples. HP sterilized samples have the highest water contact angle $\left(68^{\circ}\right)$ in this case compared to EtO and UV sterilized samples (water contact angles of $65^{\circ}$ and $58^{\circ}$ respectively). Furthermore, for air plasma treatment, there is a big variance in cell number between samples after HP sterilization. This is attributable to the non-homogeneity of the air plasma-treated films resulting in different cell adhesion patterns. Interestingly, despite the good initial attachment, the cell number on EtO sterilized samples falls below the level of tissue culture plastic after 7 days of proliferation for both plasma treatments. This can be due to the toxicity of the residual EtO causing the death of some cells during the lag-stage. The lag-stage is the period following 
the adhesion stage and corresponding to the adaptation of the cells to their environment. The cells that remain alive during this period, undergo the proliferation process ${ }^{52}$. HP and UV sterilized samples on the other hand clearly outperform tissue culture plastic in terms of proliferation. Especially for the argon plasma-treated samples sterilized by HP, the combination of a hydrophilic surface and higher roughness seems to have beneficial effects on cell numbers. Ahn et al. also reported that the mutual effect of a hydrophilic and rough surface enhances the adhesion and proliferation of ADSCs ${ }^{50}$. These beneficial effects are less pronounced on air plasma-treated samples because of the non-homogenous surface, but are still present.
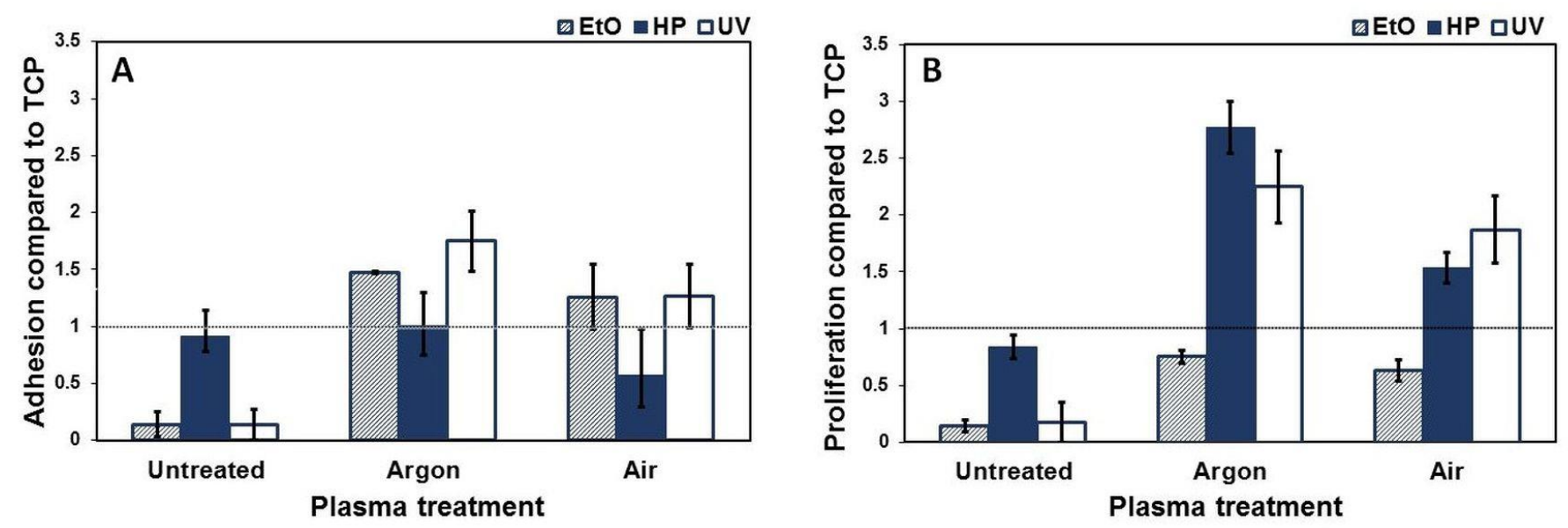

Fig 13. Ratio of cells attached to PCL films after (A) $24 \mathrm{~h}$ and (B) 7 days compared to tissue culture plastic (TCP). Error bars equal 95\% confidence interval. The dotted line represents the TCP value. 

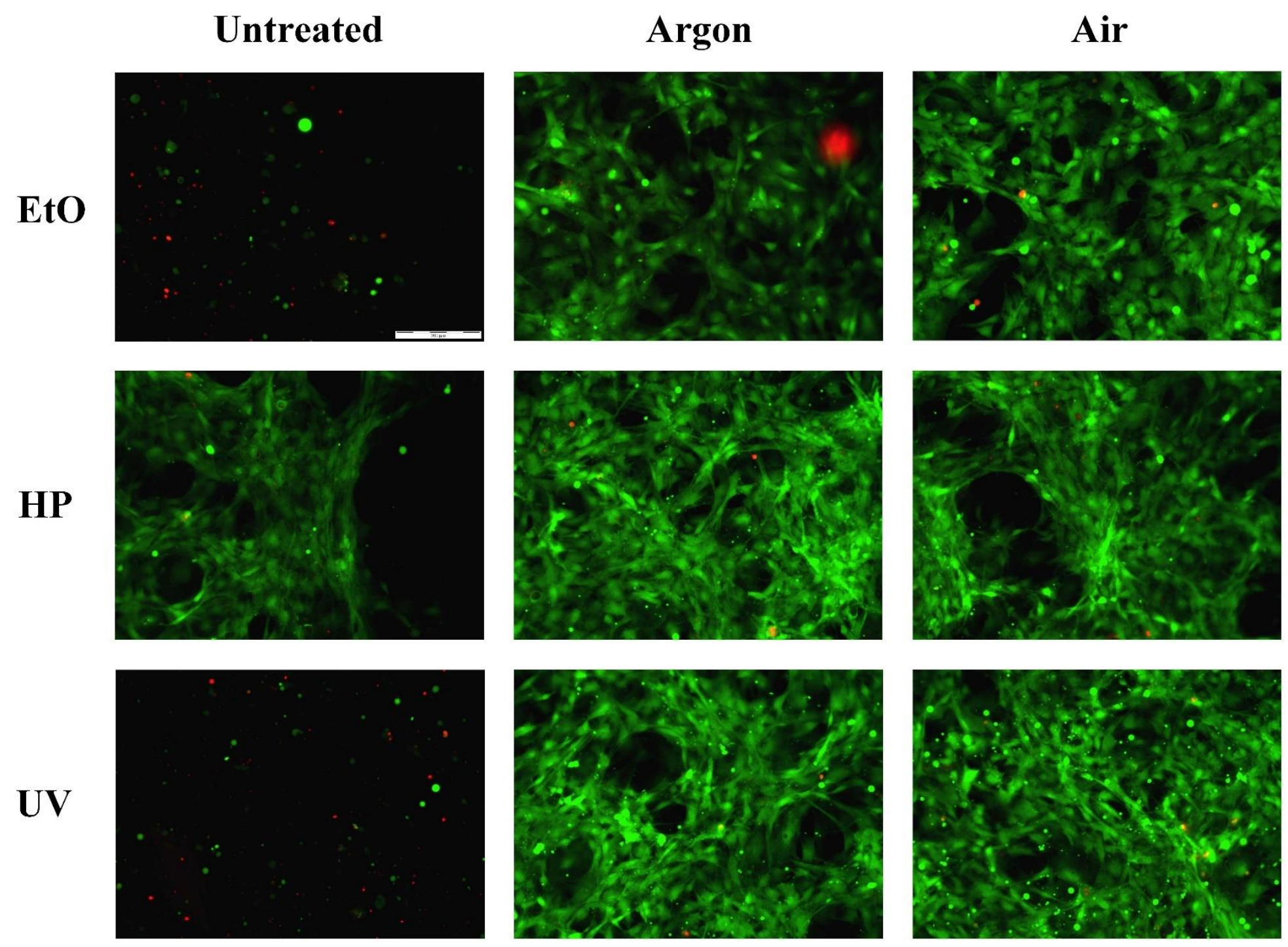

Fig 14. Live/dead staining of ADSCs on PCL films after $24 \mathrm{~h}$. Scale bar $=200 \mu \mathrm{m}$. 

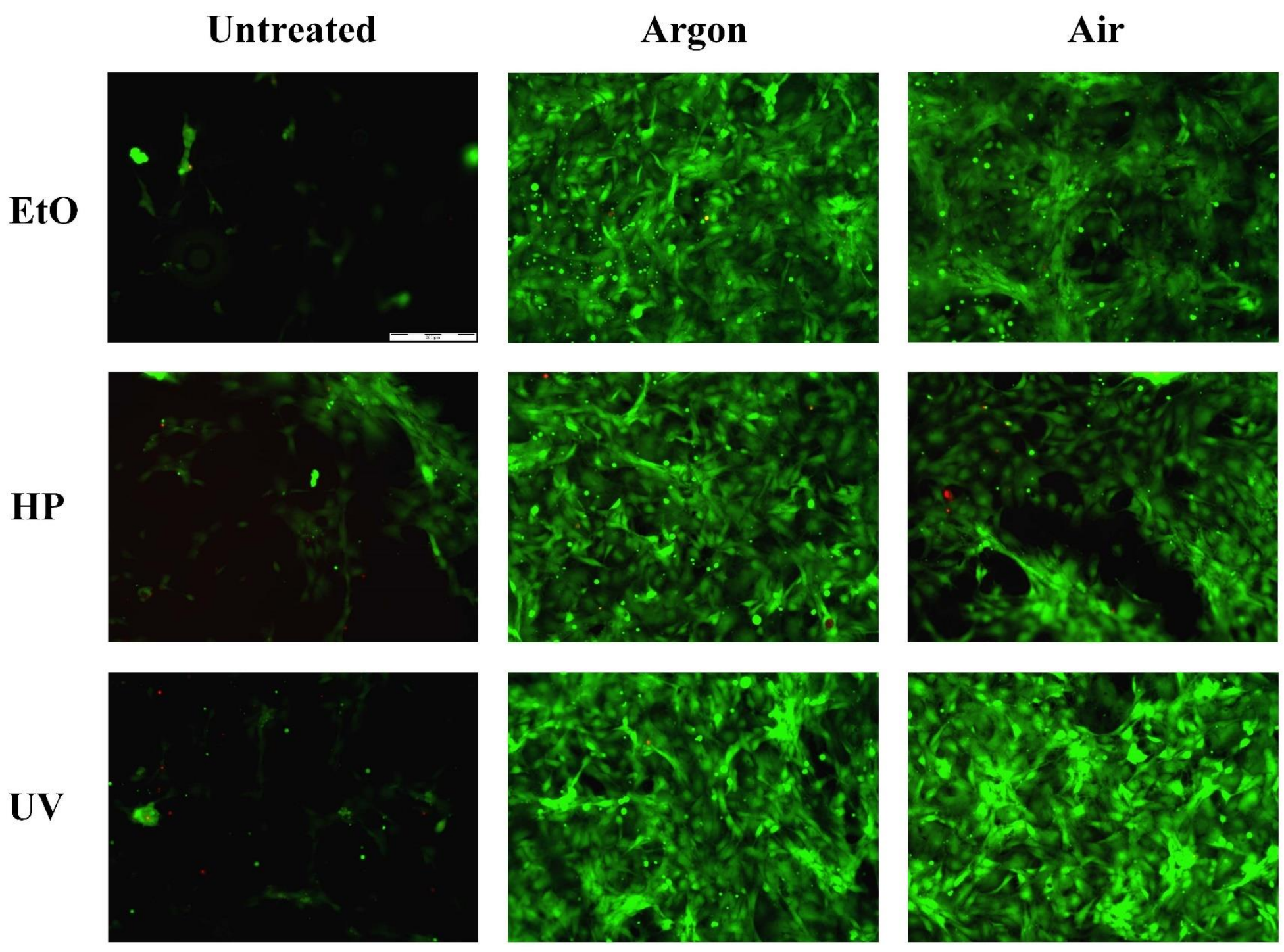

Fig 15. Live/dead staining of ADSCs on PCL films after 7 days. Scale bar $=200 \mu \mathrm{m}$.

\section{Conclusion}

This paper describes the physico-chemical surface changes and the bioreponsive properties of plasma-treated PCL films subjected to different sterilization methods. The results are divided into 2 parts: plasma surface modification of the PCL films on the one hand and sterilization of these plasma-modified samples on the other hand. For the surface modification, it can be concluded that air and argon plasmas are excellent treatments enhancing PCL wettability by incorporating oxygen-containing functionalities onto the surface. After storage in air, some of these induced groups tend to re-orientate from the surface into the bulk. This so-called ageing 
effect is more pronounced for the air plasma-treated samples compared to the argon plasmatreated samples, due to the higher cross-linking degree induced during the argon treatment. Therefore, in a trial to minimize the ageing effect, increasing the treatment time is shown beneficial for the air treated samples since it increases the cross-linking degree and thus limits the polymer chains movements. PCL surface morphology remains unchanged after plasma treatment. However, extended plasma exposure times cause a surface etching leading to PCL degradation that is enhanced in the case of air plasma treatment. Besides the beneficial surface modification, the potential of plasma to sterilize PCL is studied by varying plasma exposure times in a range that ensures a good surface modification while avoiding PCL degradation. Although an increased percentage of sterility is observed with increasing plasma exposure time, PCL films remain incompletely sterile. Therefore, plasma-modified PCL films are subjected to $\mathrm{UV}, \mathrm{H}_{2} \mathrm{O}_{2}$ plasma (HP) and ethylene oxide (EtO) sterilizations. For the three sterilizations, an improved cell adhesion and a higher proliferation rate are observed on plasma-treated films compared to the untreated ones. An increase in WCA is observed after EtO sterilization, due to the modification of the PCL chain ends reacting with EtO molecules. These chemical modifications, together with EtO toxicity, lead to the lowest cell proliferation rate compared to the other sterilizations. HP sterilization provokes a decrease in WCA of the untreated samples attributable to a surface oxidation occurring during the exposure to the highly reactive $\mathrm{H}_{2} \mathrm{O}_{2}$ and during the plasma phase. However, an increase in WCA is detected for the plasma-treated samples, presumably due to the scission of some of the hydrophilic bonds generated during the previous air or argon plasma treatment. Moreover, HP sterilization increases the roughness and modifies the morphology of the films, in particular a drastic alteration was observed for the air plasma-treated samples. The increased roughness of the HP sterilized samples is shown to enhance the cellular proliferation, but the physical alterations might interfere with the structural integrity when it comes to 3D scaffolds. Overall, of the three sterilizations, UV is revealed the most effective for plasma-treated PCL films, since no physico-chemical surface alterations are noticed after an exposure of $3 \mathrm{~h}$ and good cellular performances are detected. A subsequent study will examine whether UV sterilization will also be the most suitable for plasma-treated PCL nanofibers compared to HP and EtO.

Acknowledgements The research leading to these results has received funding from the European Research Council under the European Union's Seventh Framework Program (FP/2007-2013): ERC Grant Agreement number 279022 (PLASMAPOR) and ERC Grant Agreement number 335929 (PLASMATS). The authors also acknowledge the support of the Special Research Fund (BOF) of Ghent University. 


\section{$\underline{\text { References }}$}

(1) Cheng, Z.; Teoh, S.-H., Surface modification of ultra thin poly ( $\varepsilon$-caprolactone) films using acrylic acid and collagen. Biomaterials 2004, 25 (11), 1991-2001.

(2) Woodruff, M. A.; Hutmacher, D. W., The return of a forgotten polymer-Polycaprolactone in the 21st century. Progress in Polymer Science 2010, 35 (10), 1217-1256.

(3) Jacobs, T.; Declercq, H.; De Geyter, N.; Cornelissen, R.; Dubruel, P.; Leys, C.; Morent, R., Improved cell adhesion to flat and porous plasma-treated poly-epsilon-caprolactone samples. Surface \& Coatings Technology 2013, 232, 447-455.

(4) Yildirim, E. D.; Besunder, R.; Guceri, S.; Allen, F.; Sun, W., Fabrication and plasma treatment of 3D polycaprolactane tissue scaffolds for enhanced cellular function. Virtual and Physical Prototyping 2008, 3 (4), 199-207.

(5) Abedalwafa, M.; Wang, F.; Wang, L.; Li, C., Biodegradable Poly-Epsilon-Caprolactone (PCL) for Tissie Engineering Applications: a Review Reviews on Advanced Materials Science 2013, 34 (2), 123140.

(6) Domingos, M.; Intranuovo, F.; Gloria, A.; Gristina, R.; Ambrosio, L.; Bartolo, P. J.; Favia, P., Improved osteoblast cell affinity on plasma-modified 3-D extruded PCL scaffolds. Acta Biomaterialia 2013, 9 (4), 5997-6005.

(7) Yildirim, E. D.; Ayan, H.; Vasilets, V. N.; Fridman, A.; Guceri, S.; Friedman, G.; Sun, W., Effect of dielectric barrier discharge plasma on the attachment and proliferation of osteoblasts cultured over poly(epsilon-caprolactone) scaffolds (vol 4, pg 58, 2007). Plasma Processes and Polymers 2008, 5 (4), 397-397.

(8) Yan, D.; Jones, J.; Yuan, X.; Xu, X.; Sheng, J.; Lee, J. C. M.; Ma, G.; Yu, Q., Plasma Treatment of Random and Aligned Electrospun PCL Nanofibers. Journal of Medical and Biological Engineering 2013, $33(2), 171-178$.

(9) Cipitria, A.; Skelton, A.; Dargaville, T. R.; Dalton, P. D.; Hutmacher, D. W., Design, fabrication and characterization of PCL electrospun scaffolds-a review. Journal of Materials Chemistry 2011, 21 (26), 9419-9453.

(10) Ma, Z.; Mao, Z.; Gao, C., Surface modification and property analysis of biomedical polymers used for tissue engineering. Colloids and Surfaces B-Biointerfaces 2007, 60 (2), 137-157.

(11) Morent, R.; De Geyter, N.; Desmet, T.; Dubruel, P.; Leys, C., Plasma Surface Modification of Biodegradable Polymers: A Review. Plasma Processes and Polymers 2011, 8 (3), 171-190.

(12) Martins, A.; Pinho, E. D.; Faria, S.; Pashkuleva, I.; Marques, A. P.; Reis, R. L.; Neves, N. M., Surface Modification of Electrospun Polycaprolactone Nanofiber Meshes by Plasma Treatment to Enhance Biological Performance. Small 2009, 5 (10), 1195-1206.

(13) Yang, J.; Bei, J.; Wang, S., Enhanced cell affinity of poly (d,I-lactide) by combining plasma treatment with collagen anchorage. Biomaterials 2002, 23 (12), 2607-2614.

(14) Rhodes, N. P.; Wilson, D. J.; Williams, R. L., The effect of gas plasma modification on platelet and contact phase activation processes. Biomaterials 2007, 28 (31), 4561-4570.

(15) Abbasi, N.; Soudi, S.; Hayati-Roodbari, N.; Dodel, M.; Soleimani, M., The Effects of Plasma Treated Electrospun Nanofibrous Poly (epsilon-caprolactone) Scaffolds with Different Orientations on Mouse Embryonic Stem Cell Proliferation. Cell Journal 2014, 16 (3), 245-254.

(16) Yan, D.; Jones, J.; Yuan, X. Y.; Xu, X. H.; Sheng, J.; Lee, J. C. M.; Ma, G. Q.; Yu, Q. S., Plasma treatment of electrospun PCL random nanofiber meshes (NFMs) for biological property improvement. Journal of Biomedical Materials Research Part A 2013, 101 (4), 963-972.

(17) Lee, H.-U.; Jeong, Y.-S.; Jeong, S.-Y.; Park, S.-Y.; Bae, J.-S.; Kim, H.-G.; Cho, C.-R., Role of reactive gas in atmospheric plasma for cell attachment and proliferation on biocompatible poly epsilon-caprolactone film. Applied Surface Science 2008, 254 (18), 5700-5705.

(18) Lee, H. U.; Jeong, Y. S.; Koh, K. N.; Jeong, S. Y.; Kim, H.-G.; Bae, J. S.; Cho, C. R., Contribution of power on cell adhesion using atmospheric dielectric barrier discharge (DBD) plasma system. Current Applied Physics 2009, 9 (1), 219-223. 
DBD treatment of polyethylene terephthalate: Atmospheric versus medium pressure treatment.

Surface \& Coatings Technology 2008, 202 (13), 3000-3010.

(20) Jacobs, T.; De Geyter, N.; Morent, R.; Desmet, T.; Dubruel, P.; Leys, C., Plasma treatment of polycaprolactone at medium pressure. Surface \& Coatings Technology 2011, 205, S543-S547.

(21) Braghirolli, D. I.; Steffens, D.; Quintiliano, K.; Acasigua, G. A. X.; Gamba, D.; Fleck, R. A.; Petzhold, C. L.; Pranke, P., The effect of sterilization methods on electronspun poly(lactide-coglycolide) and subsequent adhesion efficiency of mesenchymal stem cells. Journal of Biomedical Materials Research Part B: Applied Biomaterials 2014, 102 (4), 700-708.

(22) Andrews, K. D.; Hunt, J. A.; Black, R. A., Effects of sterilisation method on surface topography and in-vitro cell behaviour of electrostatically spun scaffolds. Biomaterials 2007, 28 (6), 1014-1026.

(23) Ahmed, M.; Punshon, G.; Darbyshire, A.; Seifalian, A. M., Effects of sterilization treatments on bulk and surface properties of nanocomposite biomaterials. Journal of Biomedical Materials Research Part B-Applied Biomaterials 2013, 101 (7), 1182-1190.

(24) Moisan, M.; Barbeau, J.; Moreau, S.; Pelletier, J.; Tabrizian, M.; Yahia, L. H., Low-temperature sterilization using gas plasmas: a review of the experiments and an analysis of the inactivation mechanisms. International Journal of Pharmaceutics 2001, 226 (1-2), 1-21.

(25) Shintani, H.; Sakudo, A.; Burke, P.; McDonnell, G., Gas plasma sterilization of microorganisms and mechanisms of action (Review). Experimental and Therapeutic Medicine 2010, 1 (5), 731-738.

(26) Lerouge, S.; Wertheimer, M. R.; Yahia, L. H., Plasma Sterilization: A Review of Parameters, Mechanisms, and Limitations. Plasmas and Polymers 2001, 6 (3), 175-188.

(27) Lerouge, S.; Wertheimer, M. R.; Marchand, R.; Tabrizian, M.; Yahia, L., Effect of gas composition on spore mortality and etching during low-pressure plasma sterilization. Journal of Biomedical Materials Research 2000, 51 (1), 128-135.

(28) Rainer, A.; Centola, M.; Spadaccio, C.; Gherardi, G.; Genovese, J. A.; Licoccia, S.; Trombetta, M., Comparative study of different techniques for the sterilization of poly-L-lactide electrospun microfibers: effectiveness vs. material degradation. International Journal of Artificial Organs 2010, 33 (2), 76-85.

(29) Valente, T. A. M.; Silva, D. M.; Gomes, P. S.; Fernandes, M. H.; Santos, J. D.; Sencadas, V., Effect of Sterilization Methods on Electrospun Poly(lactic acid) (PLA) Fiber Alignment for Biomedical Applications. Acs Applied Materials \& Interfaces 2016, 8 (5), 3241-3249.

(30) Holy, C. E.; Cheng, C.; Davies, J. E.; Shoichet, M. S., Optimizing the sterilization of PLGA scaffolds for use in tissue engineering. Biomaterials 2000, 22 (1), 25-31.

(31) Peniston, S. J.; Choi, S. J., Effect of sterilization on the physicochemical properties of molded poly(L-lactic acid). Journal of Biomedical Materials Research Part B-Applied Biomaterials 2007, 80B (1), 67-77.

(32) Mendes, G. C. C.; Brandao, T. R. S.; Silva, C. L. M., Ethylene oxide sterilization of medical devices: A review. American Journal of Infection Control 2007, 35 (9), 574-581.

(33) Fischbach, C.; Tessmar, J.; Lucke, A.; Schnell, E.; Schmeer, G.; Blunk, T.; Gopferich, A., Does UV irradiation affect polymer properties relevant to tissue engineering? Surface Science 2001, 491 (3), 333-345.

(34) Wagner, H. E.; Brandenburg, R.; Kozlov, K. V.; Sonnenfeld, A.; Michel, P.; Behnke, J. F., The barrier discharge: basic properties and applications to surface treatment. Vacuum 2003, 71 (3), 417436.

(35) Massines, F.; Gherardi, N.; Fornelli, A.; Martin, S., Atmospheric pressure plasma deposition of thin films by Townsend dielectric barrier discharge. Surface \& Coatings Technology 2005, 200 (5-6), 1855-1861.

(36) Massines, F.; Gouda, G.; Gherardi, N.; Duran, M.; Croquesel, E., The Role of Dielectric Barrier Discharge Atmosphere and Physics on Polypropylene Surface Treatment. Plasmas and Polymers 2001, $6(1), 35-49$.

(37) El-Zeer, D. M. S., A. A.; Rashed, U. M.; Abd-Elbaset, T. A.; Ghalab, S. , A Comparative Study between the Filamentary and Glow Modes of DBD Plasma in the Treatment of Wool Fibers. Journal of Engineering Research and Applications 2014, 4 (3), 401-410. 
(38) Marmur, A., Soft contact: measurement and interpretation of contact angles. Soft Matter 2006, 2 (1), 12-17.

(39) Hegemann, D.; Brunner, H.; Oehr, C., Plasma treatment of polymers for surface and adhesion improvement. Nuclear Instruments \& Methods in Physics Research Section B-Beam Interactions with Materials and Atoms 2003, 208, 281-286.

(40) Morent, R.; De Geyter, N.; Trentesaux, M.; Gengembre, L.; Dubruel, P.; Leys, C.; Payen, E., Influence of Discharge Atmosphere on the Ageing Behaviour of Plasma-Treated Polylactic Acid. Plasma Chemistry and Plasma Processing 2010, 30 (4), 525-536.

(41) Morent, R.; De Geyter, N.; Leys, C.; Gengembre, L.; Payen, E., Study of the ageing behaviour of polymer films treated with a dielectric barrier discharge in air, helium and argon at medium pressure. Surface \& Coatings Technology 2007, 201 (18), 7847-7854.

(42) Slepicka, P.; Kasalkova, N. S.; Stranska, E.; Bacakova, L.; Svorcik, V., Surface characterization of plasma treated polymers for applications as biocompatible carriers. Express Polymer Letters 2013, 7 (6), 535-545.

(43) Manakhov, A.; Necas, D.; Cechal, J.; Pavlinak, D.; Elias, M.; Zajickova, L., Deposition of stable amine coating onto polycaprolactone nanofibers by low pressure cyclopropylamine plasma polymerization. Thin Solid Films 2015, 581, 7-13.

(44) De Geyter, N.; Morent, R.; Desmet, T.; Trentesaux, M.; Gengembre, L.; Dubruel, P.; Leys, C.; Payen, E., Plasma modification of polylactic acid in a medium pressure DBD. Surface \& Coatings Technology 2010, 204 (20), 3272-3279.

(45) Domingos, M.; Chiellini, F.; Cometa, S.; Giglio, E. D.; Grillo-Fernandes, E.; Bartolo, P.; Chiellini, E., Evaluation of in vitro degradation of PCL scaffolds fabricated via BioExtrusion - Part 2: Influence of pore size and geometry. Virtual and Physical Prototyping 2011, 6 (3), 157-165.

(46) Pappa, A. M.; Karagkiozaki, V.; Krol, S.; Kassavetis, S.; Konstantinou, D.; Pitsalidis, C.; Tzounis, L.; Pliatsikas, N.; Logothetidis, S., Oxygen-plasma-modified biomimetic nanofibrous scaffolds for enhanced compatibility of cardiovascular implants. Beilstein Journal of Nanotechnology 2015, 6, 254262.

(47) Moisan, M.; Barbeau, J.; Crevier, M. C.; Pelletier, J.; Philip, N.; Saoudi, B., Plasma sterilization. Methods mechanisms. Pure and Applied Chemistry 2002, 74 (3), 349-358.

(48) Lerouge, S.; Tabrizian, M.; Wertheimer, M. R.; Marchand, R.; Yahia, L., Safety of plasma-based sterilization: Surface modifications of polymeric medical devices induced by Sterrad((R)) and Plazlyte (TM) processes. Bio-Medical Materials and Engineering 2002, 12 (1), 3-13.

(49) Lerouge, S.; Guignot, C.; Tabrizian, M.; Ferrier, D.; Yagoubi, N.; Yahia, L. H., Plasma-based sterilization: Effect on surface and bulk properties and hydrolytic stability of reprocessed polyurethane electrophysiology catheters. Journal of Biomedical Materials Research 2000, 52 (4), 774-782.

(50) Ahn, H. H.; Lee, I. W.; Lee, H. B.; Kim, M. S., Cellular Behavior of Human Adipose- Derived Stem Cells on Wettable Gradient Polyethylene Surfaces. International Journal of Molecular Sciences 2014, 15 (2), 2075-2086.

(51) Bacakova, L.; Filova, E.; Parizek, M.; Ruml, T.; Svorcik, V., Modulation of cell adhesion, proliferation and differentiation on materials designed for body implants. Biotechnology Advances 2011, 29 (6), 739-767.

(52) Slepicka, P.; Trostova, S.; Kasalkova, N. S.; Kolska, Z.; Sajdl, P.; Svorcik, V., Surface Modification of Biopolymers by Argon Plasma and Thermal Treatment. Plasma Processes and Polymers 2012, 9 (2), 197-206. 